Wang et al.

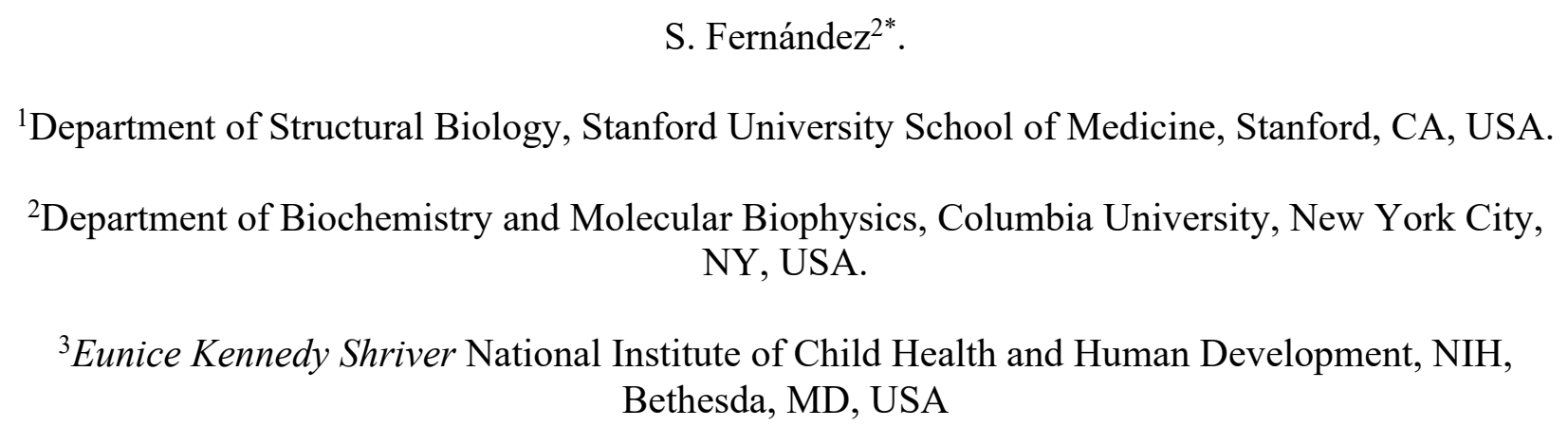

Abstract

Recognition of a start codon by the first aminoacyl-tRNA (Met-tRNA ${ }_{i}^{\text {Met }}$ ) determines the reading frame of messenger RNA (mRNA) translation by the ribosome. In eukaryotes, the

GTPase eIF5B collaborates in the correct positioning of Met-tRNA ${ }_{i}{ }^{M e t}$ on the ribosome in the

later stages of translation initiation, gating entrance into elongation. Leveraging the long residence time of eIF5B on the ribosome recently identified by single-molecule fluorescence measurements, we determined the cryoEM structure of the naturally long-lived ribosome complex with eIF5B and Met-tRNA ${ }_{i}^{\text {Met }}$ immediately before transition into elongation. The structure uncovered an unexpected, eukaryotic specific and dynamic fidelity checkpoint implemented by eIF5B in concert with components of the large ribosomal subunit.

One sentence summary:

26 CryoEM structure of a naturally long-lived translation initiation intermediate with Met-tRNA ${ }_{i}^{\text {Met }}$ and eIF5B 27 post GTP hydrolysis. 


\section{Wang et al.}

* To whom correspondence could be addressed to puglisi@stanford.edu (JDP) and

29 isf2106@cumc.columbia.edu (ISF).

30

Protein synthesis starts with the assembly of a ribosomal complex at the start site on the mRNA (1). Eukaryotes employ numerous translation initiation factors (eIFs) to achieve the $80 \mathrm{~S}$ initiation complex (IC) with the initiator aminoacyl-tRNA (Met-tRNA ${ }_{i}{ }^{\mathrm{Met}}$ ) and the AUG start codon of the mRNA programmed in the ribosomal peptidyl-tRNA site (P site) (2). The 40S small ribosomal subunit, accompanied by eIFs and Met-tRNA $_{i}{ }^{\text {Met }}$, is recruited to the 5'-UnTranslated Region (5'-UTR) of the 7-methylguanosine-capped mRNA (3). This is followed by a dynamic inspection of the 5'-UTR in search of the correct AUG codon as a start site, a process termed "scanning" $(4,5)$. Upon AUG recognition by the Met-tRNA ${ }_{i}^{\text {Met }}$ anticodon, a series of eIF reorganizations and departures coupled to ribosomal conformational rearrangements occurs, resulting in a post-scanning $48 \mathrm{~S}$ preinitiation complex (PIC) (6-8). This $48 \mathrm{~S}$ PIC is then joined by the $60 \mathrm{~S}$ large ribosomal subunit to form the 80S IC, catalyzed by the universally conserved GTPase eIF5B (Fig. 1A) $(9,10)$. Using single-molecule fluorescence methods, we recently revealed that maturation of the Saccharomyces cerevisiae 80S IC to the elongation-competent state (80S EC) with an exposed codon in the A site for aminoacyl-tRNA delivery is gated by the slow eIF5B dissociation from the complex (Fig. S1, A and B) (11). This dissociation of eIF5B requires GTP hydrolysis, with the timing of its dissociation critical to stringent start codon selection.

These dynamics results left unanswered whether the slow dissociation of eIF5B was limited by its GTPase-activation/GTP-hydrolysis, Pi release, and/or eIF5B:GDP dissociation. Previous cryoEM reconstructions have described the architectures of the 80S IC bound with eIF5B:GDPCP at medium resolution, representing snapshots of the assembly prior to eIF5B GTP hydrolysis $(12,13)$. In addition, Met-tRNA $_{i}{ }^{\text {Met }}$ has sequence features that allow it to bind directly to the $\mathrm{P}$ site of the ribosome during initiation, unlike elongator tRNAs (14-16). Here, guided by the kinetics determined by our previous singlemolecule fluorescence measurements, we performed cryoEM analysis of the on-pathway initiation 
bioRxiv preprint doi: https://doi.org/10.1101/2020.05.30.125153; this version posted May 31, 2020. The copyright holder for this preprint (which

was not certified by peer review) is the author/funder, who has granted bioRxiv a license to display the preprint in perpetuity. It is made available under aCC-BY 4.0 International license.

Wang et al.

53 complexes to provide high-resolution information on the molecular mechanism by which eIF5B escorts the

54 initiator tRNA into the ribosomal P site and gates the transition from initiation to elongation.

55 Leveraging the slow dissociation of eIF5B from the 80S IC in the native initiation pathway (average

56 lifetime of the eIF5B-bound $80 \mathrm{~S}$ state is $30-60 \mathrm{~s}$ at $\left.20^{\circ} \mathrm{C}\right)(11)$, we prepared and froze samples at a pre-

57 steady-state reaction timepoint (40 s, Fig. 1B, Fig. S1 and Methods) corresponding to when $\sim 60 \%$ of the

58 assembled 80 S should be bound with eIF5B (80S IC) after mixing 48S PICs with eIF5B:GTP and 60S.

59 Image processing and 3D classification in Relion3 $(17,18)$ identified a homogeneous class of

$60 \sim 70 \%$ of the total pool of $80 \mathrm{~S}$ particles, allowing the reconstruction of a $3 \mathrm{D}$ map with a global

61 resolution of $2.9 \AA$ (Fig. S2, S3 and S4). The reconstruction shows clear density for a tRNA in the

62 surroundings of the P site and density for all domains of eIF5B (Fig. 1C). A further analysis of the

63 map revealed excellent densities for domain III (DIII), the connecting $\alpha$-helix 12 (Fig. 1C and D,

$64 \mathrm{~h} 12(19))$ and especially for domain IV (DIV) of eIF5B, as well as for the Met-tRNA ${ }_{i}{ }^{\text {Met }}$ and the

65 start-codon of the mRNA (Fig. 1C and D and Fig. S4). Less well resolved were domains II and G

66 of eIF5B and the elbow region of Met-tRNA ${ }_{i}^{\text {Met }}$ (Fig. S3).

In our reconstruction, DIV of eIF5B is tightly packed against the peptidyl transferase center

68 (PTC) of the large subunit where it contacts the ${ }_{73} \mathrm{ACCA}_{76}$-Met end of Met-tRNA ${ }_{i}{ }^{M e t}$ (Fig. 2). The

69 close interaction of eIF5B DIV with the acceptor stem of Met-tRNA ${ }_{i}{ }^{\text {Met }}$ enforces a change in the

70 trajectory of the ${ }_{73} \mathrm{ACCA}_{76}$-Met end when compared with the position adopted by the acceptor

71 stem on an elongation peptidyl-tRNA in a canonical configuration (Movie S1) (20). This distortion

72 is not limited to the ${ }_{73} \mathrm{ACCA}_{76}-\mathrm{Met}$ of $\mathrm{tRNA}_{\mathrm{i}}{ }^{\mathrm{Met}}$, as the whole acceptor stem is distorted compared

73 with its position in an elongation tRNA (Fig. 2B and C). The cluster of G-C base pairs of the

74 acceptor stem specific to Met-tRNA ${ }_{i}{ }^{\text {Met }}$ seems to play a pivotal role in this context, allowing a

75 specific distortion of this stem as the Met-tRNA ${ }_{i}^{\text {Met }}$ simultaneously interacts with eIF5B and the

76 start-codon (Fig. 2A and B and Fig. S5). Basic residues of the domain IV of eIF5B make specific 
bioRxiv preprint doi: https://doi.org/10.1101/2020.05.30.125153; this version posted May 31, 2020. The copyright holder for this preprint (which

was not certified by peer review) is the author/funder, who has granted bioRxiv a license to display the preprint in perpetuity. It is made available under aCC-BY 4.0 International license.

Wang et al.

77 interactions with this G-C base pairs cluster (21); Arg955 of eIF5B contacts the base of G70 of

78 Met-tRNA ${ }_{i}{ }^{\text {Met }}$ from the major groove of the acceptor stem (Fig. 2E and F). Although mutating

79 Arg955 to Ala in eIF5B did not substantially alter the growth rate of yeast in rich medium, the

80 mutant strain could not grow under amino acid starvation conditions (Fig. 2G), suggesting

81 impaired GCN4 expression that could result from ribosomes scanning past the start codon (termed

82 "leaky scanning") of the stimulatory first upstream open reading frame (uORF1) in the mRNA.

83 Thus, the interaction between eIF5B Arg955 and Met-tRNA ${ }_{i}{ }^{\text {Met }}$ G70 may also play an important

84 role in start-site selection. Consistently, deletion of eIF5B DIV has also been shown to enhance

85 leaky scanning in yeast (19).

In contrast, the anticodon arm of Met-tRNA ${ }_{i}{ }^{\text {Met }}$ features a configuration very similar to that

87 described for a peptidyl-tRNA in an elongation, canonical state (Fig. 2D, Fig. S5B and Movie S1)

88 (20). Anticodon bases C34, A35 and U36 have reached their final elongation position, which

89 would allow a productive transition into elongation. The rigidity contributed by the G-C cluster of

90 base-pairs in the ASL seems to play an important role, allowing a local distortion that guarantees

91 an ideal positioning of the anticodon bases to maximize the interaction with the AUG codon (15),

92 while allowing the tRNA to bend at the elbow region of T-loop/D-loop tertiary interaction to

93 prevent accommodation of the aminoacyl-acceptor stem to the elongation state (Fig. 2B and C).

94 Thus, both G-C base pair clusters at the acceptor stem and the anticodon arm of Met-tRNA ${ }_{i}{ }^{\text {Met }}$ are

95 essential to allow a specific conformation of the Met-tRNA ${ }_{i}{ }^{M e t}$ on the $\mathrm{P}$ site in both the early (21)

96 and late stages of initiation (14).

For the mRNA, we could unambiguously identify six nucleotides including the AUG start

98 codon and the three nucleotides immediately upstream (Fig. 3). Only weak densities ascribable to

99 the A site codon could be observed, and no ordered RNA density could be identified at the entry 
bioRxiv preprint doi: https://doi.org/10.1101/2020.05.30.125153; this version posted May 31, 2020. The copyright holder for this preprint (which

was not certified by peer review) is the author/funder, who has granted bioRxiv a license to display the preprint in perpetuity. It is made available under aCC-BY 4.0 International license.

Wang et al.

100

101

102

103

104

105

106

107

108

109

110

111

112

113

114

115

116

117

118

119

120

121

nor exit sites of the mRNA channel on the 40S. This is in marked contrast with 48S PIC structures from earlier initiation stages, in which long stretches of the mRNA from the entry to the exit sites were well resolved (5), pinpointing a less prominent role of mRNA/40S interactions once initiation has progressed into its later stages.

The codon-anticodon interaction observed in our reconstruction is virtually identical to a canonical cognate pair (Fig. 3B and C) (20). Nucleotides C1637 and U1191 of the 18S rRNA at the base of the $40 \mathrm{~S} \mathrm{P}$ site bracket the base pair mRNA- ${ }_{3} \mathrm{G}: \mathrm{C}_{34}-\mathrm{RNA}_{\mathrm{i}}{ }^{\mathrm{Met}}$ in a very similar configuration as in an elongation complex (Fig. 3C and D). Additionally, ribosomal bases G1150 and G904 engage mRNA nucleotides at position -1 and -3, respectively, in stacking interactions in a similar configuration as in early initiation complexes in the 48S PIC context (Fig. 3C and D) $(6,7)$. Thus, in the later stages of initiation, prior to entrance into elongation, the start-codon and its flanking residues present a hybrid configuration with bases at position $-1 /-3$ retaining key contacts with rRNA bases that are instrumental in the early positioning of the mRNA on the 40S and, at the same time, with the start-codon features characteristic of a standard conformation of an elongation state (20). Hence, the start codon-surrounding sequence, especially the bases at positions $-3 /-1$, plays an essential role along all initiation, from early "scanning" to later entrance into elongation (22).

The high quality of the map around the PTC region allowed a precise modeling, revealing specific contacts of residues of eIF5B DIV with the four terminal bases of the Met-tRNA ${ }_{i}{ }^{\text {Met }}$ as well as with ribose and phosphate backbone atoms (Fig. 4). Specifically, the base of Met-tRNA ${ }_{i}{ }^{\text {Met }}$ nucleotide A76 is narrowly monitored by eIF5B residues Glu921 and His924, which anchors the adenine moiety to eIF5B DIV (Fig. 4B and C). In this orientation, the methionyl group esterified 
bioRxiv preprint doi: https://doi.org/10.1101/2020.05.30.125153; this version posted May 31, 2020. The copyright holder for this preprint (which

was not certified by peer review) is the author/funder, who has granted bioRxiv a license to display the preprint in perpetuity. It is made available under aCC-BY 4.0 International license.

\section{Wang et al.}

122

123

124

125

126

127

128

129

130

131

132

133

134

135

136

137

138

139

140

141

142

143

144

to the 3'OH of the A76 ribose is directed towards a hydrophobic "pocket" formed by the surface of eIF5B around residue Ile874 (Fig. 4C and D and Fig. S6).

Intriguingly, this "hydrophobic pocket" is capped by a loop of ribosomal protein uL16, a component of the 60S (Fig. 4B-D and Fig. S6), which is conserved in yeast and humans. This uL16 loop, formed by residues 100 to 120 , is disordered in reported elongation $80 \mathrm{~S}$ complexes, but is well resolved in our reconstruction, allowing its modelling and refinement. Notably, this loop is stringently checked at the last step of $60 \mathrm{~S}$ biogenesis by a sophisticated cellular machinery that blocks 60S exporting to the cytoplasm if its integrity is compromised (23). No clear function has been assigned for this loop that would justify such a conserved and costly cellular machinery (24). Here, residues Ser104 to Arg110 of this loop are located in close proximity to the ${ }_{73} \mathrm{ACCA}_{76}$-Met of Met-tRNA ${ }_{i}{ }^{\text {Met }}$, in an almost parallel configuration to the phosphate backbone of the Met-tRNA ${ }_{i}^{\text {Met }}$ (Fig. 4C). Additionally, uL16 residues Leu103 and Ser104 tightly approach the eIF5B residues around Leu871 to define a narrow and hydrophobic cavity where the methionine residue is hosted (Fig. 4D and Fig. S6). No obvious contacts between the methionine moiety and either eIF5B or uL16 residues could be observed, which points towards an overall chemical requirement for an amino acid attached to an initiator tRNA in terms of size and hydrophobicity rather than a specific amino acid identity. Indeed, when $\mathrm{tRNA}_{i}{ }^{\mathrm{Met}}$ is mis-acylated with glycine, Gly-tRNA ${ }_{i}{ }^{\text {Met }}$ is active in $48 \mathrm{~S}$ PIC and 80 S formation (Fig. S7). However, subunit joining rate is $\sim 9$-fold slower and the subsequent transition to elongation became $\sim 3$-fold faster. Both effects might reflect weakened interactions between $\mathrm{tRNA}_{\mathrm{i}}^{\mathrm{Met}}$ and $\mathrm{eIF} 5 \mathrm{~B} / \mathrm{uL} 16$ when the methionine moiety was replaced by the smaller, non-hydrophobic glycine residue.

Analysis of the G domain of eIF5B that binds GTP reveals clear density for a bound nucleotide that however lacks features compatible with the presence of a $\gamma$-phosphate, implying 
bioRxiv preprint doi: https://doi.org/10.1101/2020.05.30.125153; this version posted May 31, 2020. The copyright holder for this preprint (which

was not certified by peer review) is the author/funder, who has granted bioRxiv a license to display the preprint in perpetuity. It is made available under aCC-BY 4.0 International license.

Wang et al.

145 that the nucleotide state is either GDP or GDP-Pi $(25,26)$. Moreover, switch I of eIF5B is

146 disordered, which differs from the ordered state prior to GTP hydrolysis $(25,27)$. Thus, our

147 reconstruction represents an intermediate of the 80S IC right before its transition to the elongation-

148 competent state, but post GTP hydrolysis. This is further supported by the fact that the ribosomal

149 inter-subunit configuration observed here is different from the 80S IC state prior to GTP hydrolysis

150 (Fig. S8). A $\sim 3^{\circ}$ counterclockwise rotation of the $40 \mathrm{~S}$ in relation to the $60 \mathrm{~S}$ was observed in the

151 pre-GTP hydrolysis state, which was coupled with apparent 40S head swivel (Fig. S8 (12, 13, 28)).

152 However, the eIF5B-bound 80S IC observed here presents a configuration very similar to a 153 canonical non-rotated $80 \mathrm{~S}$ complex, with virtually no rotation of the small subunit and minimal

154 swiveling of the 40S head (Fig. S8). Thus, the 80S IC will reconfigure its conformation after GTP

155 hydrolysis to a state that is more similar to the non-rotated elongation-competent state, and this

156 reconfiguration is coupled to the structural rearrangements of eIF5B.

In summary, our structural analysis of the pre-steady-state initiation complexes identified

158 a novel intermediate of the late translation initiation complex on the native reaction pathway. Our

159 results demonstrated that GTP hydrolysis is not the rate-limiting step for eIF5B dissociation from

160 the 80S IC, but the subsequent Pi release and/or eIF5B-GDP dissociation. Notably, our structure

161 describes stable interactions among Met-tRNA ${ }_{i}{ }^{\text {Met }}$, eIF5B DIV and $u L 16$ after GTP hydrolysis by

162 eIF5B. Disruption of this network of contacts is required for release of eIF5B, perhaps explaining

163 the slow eIF5B departure rate post GTP hydrolysis. Such cooperation among Met-tRNA ${ }_{i}{ }^{\text {Met }}$, an

164 initiation factor and the 60S subunit highlights a eukaryote-specific mechanism to control the 165 progression of the initiation complex into the elongation phase. 
bioRxiv preprint doi: https://doi.org/10.1101/2020.05.30.125153; this version posted May 31, 2020. The copyright holder for this preprint (which

was not certified by peer review) is the author/funder, who has granted bioRxiv a license to display the preprint in perpetuity. It is made available under aCC-BY 4.0 International license.

Wang et al.

\section{References.}

1. J. Frank, R. L. Gonzalez, Jr., Structure and dynamics of a processive Brownian motor: the translating ribosome. Annu Rev Biochem 79, 381-412 (2010).

2. C. E. Aitken, J. R. Lorsch, A mechanistic overview of translation initiation in eukaryotes. Nat Struct Mol Biol 19, 568-576 (2012).

3. R. J. Jackson, C. U. Hellen, T. V. Pestova, The mechanism of eukaryotic translation initiation and principles of its regulation. Nat Rev Mol Cell Biol 11, 113-127 (2010).

4. A. G. Hinnebusch, The scanning mechanism of eukaryotic translation initiation. Annu Rev Biochem 83, 779-812 (2014).

5. A. G. Hinnebusch, Structural Insights into the Mechanism of Scanning and Start Codon Recognition in Eukaryotic Translation Initiation. Trends Biochem Sci 42, 589-611 (2017).

6. J. L. Llacer et al., Translational initiation factor eIF5 replaces eIF1 on the 40S ribosomal subunit to promote start-codon recognition. Elife 7, (2018).

7. T. Hussain et al., Structural changes enable start codon recognition by the eukaryotic translation initiation complex. Cell 159, 597-607 (2014).

8. Y. Hashem, J. Frank, The Jigsaw Puzzle of mRNA Translation Initiation in Eukaryotes: A Decade of Structures Unraveling the Mechanics of the Process. Annu Rev Biophys, (2018).

9. T. V. Pestova et al., The joining of ribosomal subunits in eukaryotes requires eIF5B. Nature 403, 332-335 (2000).

10. T. E. Dever et al., Universal translation initiation factor IF2/eIF5B. Cold Spring Harb Symp Quant Biol 66, 417-424 (2001).

11. J. Wang et al., eIF5B gates the transition from translation initiation to elongation. Nature 573, 605-608 (2019).

12. I. S. Fernandez et al., Molecular architecture of a eukaryotic translational initiation complex. Science 342, 1240585 (2013).

13. H. Yamamoto et al., Structure of the mammalian $80 \mathrm{~S}$ initiation complex with initiation factor 5B on HCV-IRES RNA. Nat Struct Mol Biol 21, 721-727 (2014).

14. S. E. Kolitz, J. R. Lorsch, Eukaryotic initiator tRNA: finely tuned and ready for action. FEBS Lett 584, 396-404 (2010).

15. S. E. Kolitz, J. E. Takacs, J. R. Lorsch, Kinetic and thermodynamic analysis of the role of start codon/anticodon base pairing during eukaryotic translation initiation. RNA 15, 138152 (2009).

16. M. G. Acker et al., Kinetic analysis of late steps of eukaryotic translation initiation. J Mol Biol 385, 491-506 (2009).

17. S. H. Scheres, Processing of Structurally Heterogeneous Cryo-EM Data in RELION. Methods Enzymol 579, 125-157 (2016).

18. J. Zivanov et al., New tools for automated high-resolution cryo-EM structure determination in RELION-3. Elife 7, (2018).

19. B. S. Shin et al., Structural integrity of $\{$ alpha $\}$-helix $\mathrm{H} 12$ in translation initiation factor eIF5B is critical for 80S complex stability. RNA 17, 687-696 (2011).

20. S. Shao et al., Decoding Mammalian Ribosome-mRNA States by Translational GTPase Complexes. Cell 167, 1229-1240 e1215 (2016).

21. J. Dong et al., Conserved residues in yeast initiator tRNA calibrate initiation accuracy by regulating preinitiation complex stability at the start codon. Genes Dev 28, 502-520 (2014).

22. M. Kozak, The scanning model for translation: an update. J Cell Biol 108, 229-241 (1989). 
Wang et al.

23. S. O. Sulima et al., Bypass of the pre-60S ribosomal quality control as a pathway to oncogenesis. Proc Natl Acad Sci U S A 111, 5640-5645 (2014).

24. S. O. Sulima et al., Eukaryotic rpL10 drives ribosomal rotation. Nucleic Acids Res 42, 2049-2063 (2014).

25. B. Y. Huang, I. S. Fernandez, Long-range interdomain communications in eIF5B regulate GTP hydrolysis and translation initiation. Proc Natl Acad Sci U S A 117, 1429-1437 (2020).

26. B. Kuhle, R. Ficner, eIF5B employs a novel domain release mechanism to catalyze ribosomal subunit joining. EMBO J 33, 1177-1191 (2014).

27. B. S. Shin et al., rRNA suppressor of a eukaryotic translation initiation factor 5B/initiation factor 2 mutant reveals a binding site for translational GTPases on the small ribosomal subunit. Mol Cell Biol 29, 808-821 (2009).

28. T. Sprink et al., Structures of ribosome-bound initiation factor 2 reveal the mechanism of subunit association. Sci Adv 2, e1501502 (2016).

29. S. H. Scheres, RELION: implementation of a Bayesian approach to cryo-EM structure determination. J Struct Biol 180, 519-530 (2012). 
bioRxiv preprint doi: https://doi.org/10.1101/2020.05.30.125153; this version posted May 31, 2020. The copyright holder for this preprint (which

was not certified by peer review) is the author/funder, who has granted bioRxiv a license to display the preprint in perpetuity. It is made available under aCC-BY 4.0 International license.

Wang et al.

\section{$244 \quad$ Figure 1.}

245

A

B

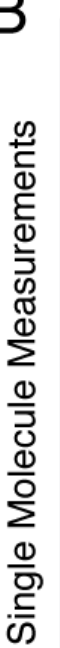

48S

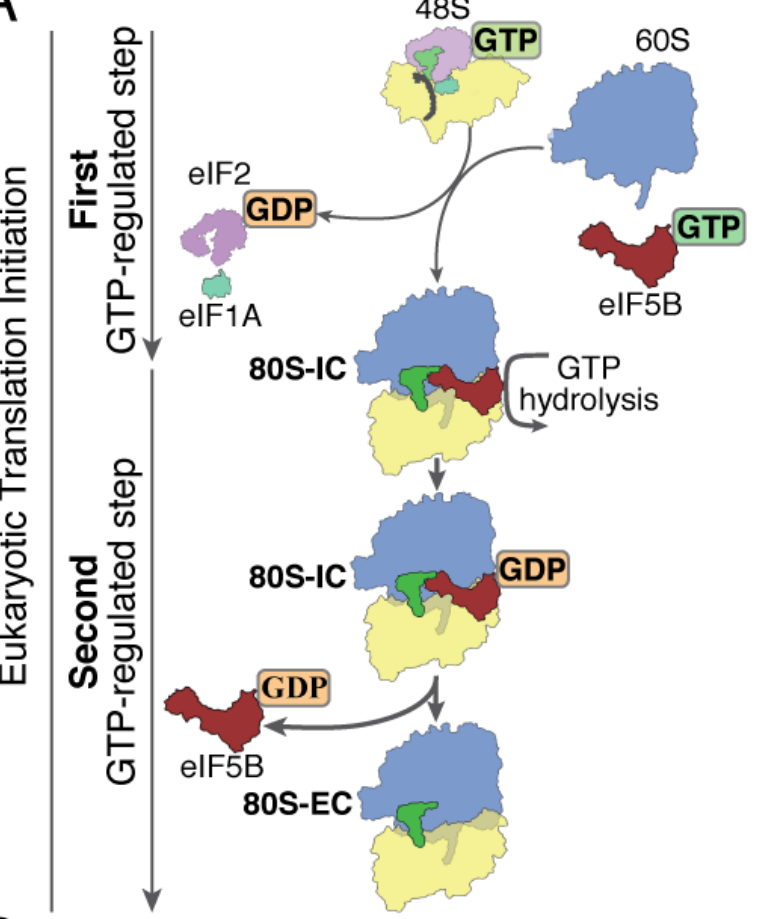

C

Event assignments
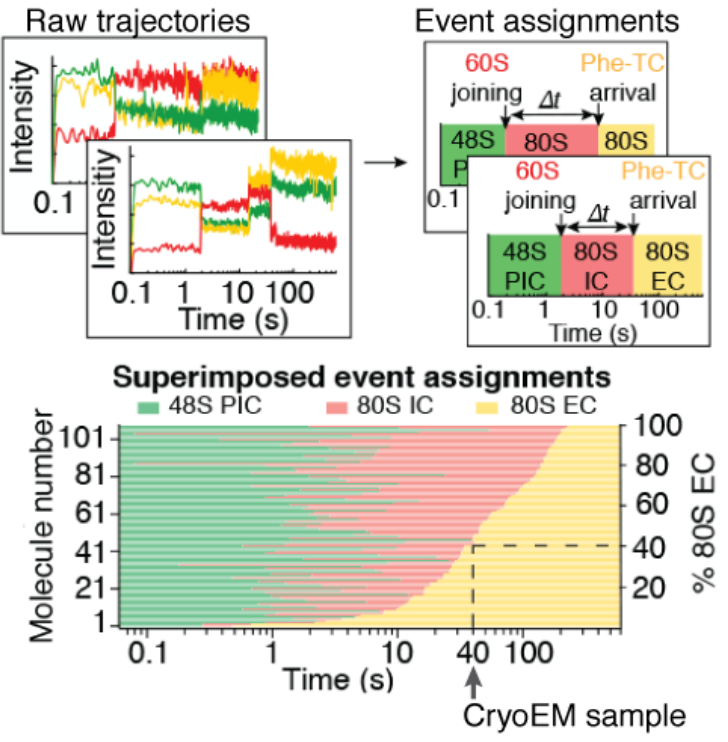

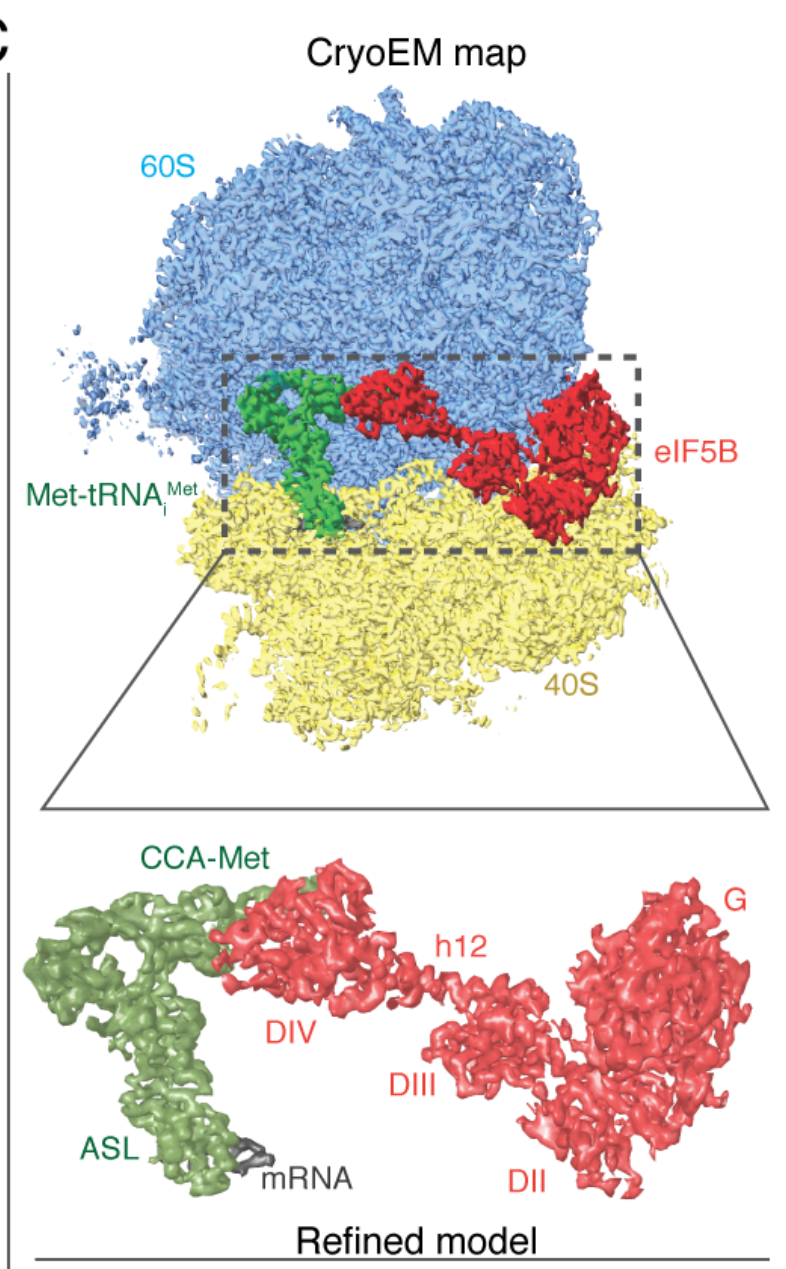

Refined model

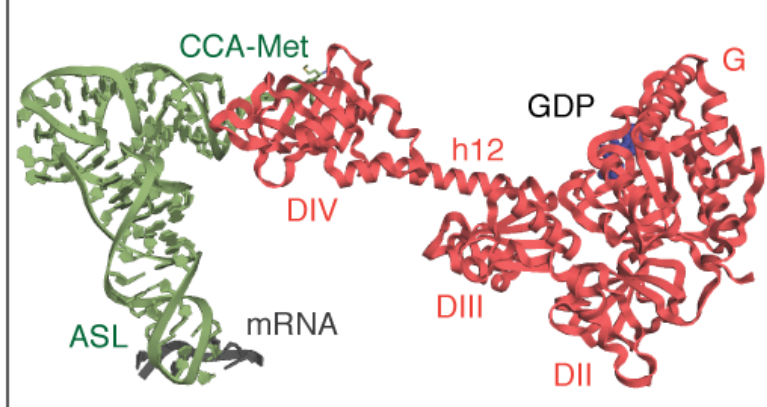


bioRxiv preprint doi: https://doi.org/10.1101/2020.05.30.125153; this version posted May 31, 2020. The copyright holder for this preprint (which

was not certified by peer review) is the author/funder, who has granted bioRxiv a license to display the preprint in perpetuity. It is made available under aCC-BY 4.0 International license.

Wang et al.

Fig. 1. CryoEM sample preparation guided by single-molecule fluorescence data and overall architecture.

251 (A) Overview of translation initiation in eukaryotes. Two steps, regulated by GTPases eIF2 and

252 eIF5B control the delivery of Met-tRNA ${ }_{i}^{\text {Met }}$. (B) CryoEM samples were prepared and froze at the

253 timepoint $40 \mathrm{~s}$ after mixing 48S PICs, eIF5B:GTP and 60S. At this timepoint, $40 \%$ of the total

$25480 \mathrm{~S}$ particles are expected to be $80 \mathrm{~S} \mathrm{EC}$, while the other $\sim 60 \%$ are $80 \mathrm{~S} \mathrm{IC}$ with eIF5B-bound, as

255 demonstrated by our previous single-molecule fluorescence data (also see Fig. S1) (11). (C)

256 Overview of the final cryoEM map obtained after maximum likelihood classifications in Relion

257 (29). Large subunit (60S) is colored in blue, small subunit (40S) yellow, Met-tRNA ${ }_{i}^{\text {Met }}$ green,

258 mRNA grey and eIF5B red. Bottom, details of the local map obtained for Met-tRNA ${ }_{i}{ }^{\text {Met }}$, mRNA

259 and eIF5B. Domain IV (DIV) of eIF5B is in close contact with the acceptor stem of Met-tRNA ${ }_{i}{ }^{\text {Met }}$.

260 (D) Stereochemically refined models for Met-tRNA ${ }_{i}{ }^{\text {Met }}$, mRNA and eIF5B with components

261 indicated.

262

263

264

265

266

267

268

269

270

271 
bioRxiv preprint doi: https://doi.org/10.1101/2020.05.30.125153; this version posted May 31, 2020. The copyright holder for this preprint (which

was not certified by peer review) is the author/funder, who has granted bioRxiv a license to display the preprint in perpetuity. It is made available under aCC-BY 4.0 International license.

Wang et al.

\section{Figure 2.}

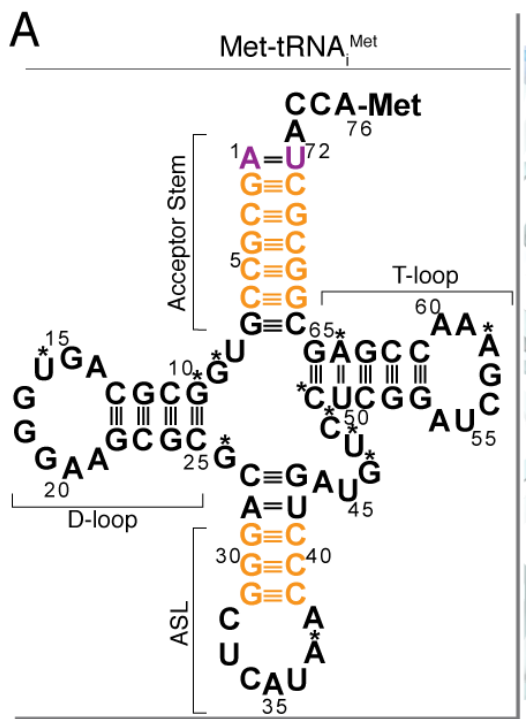

E

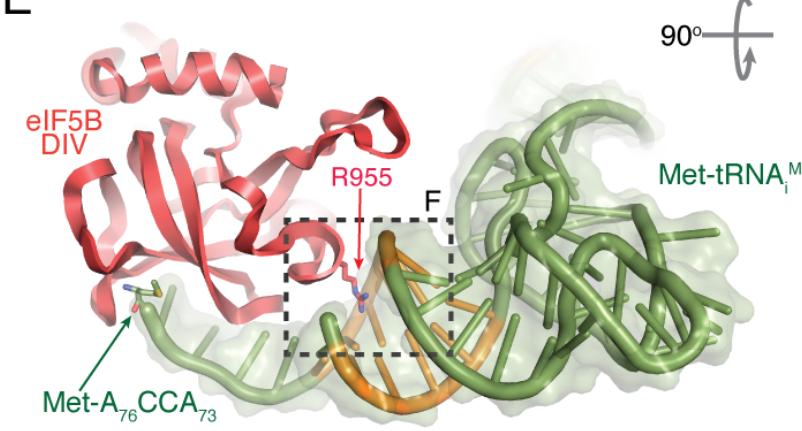

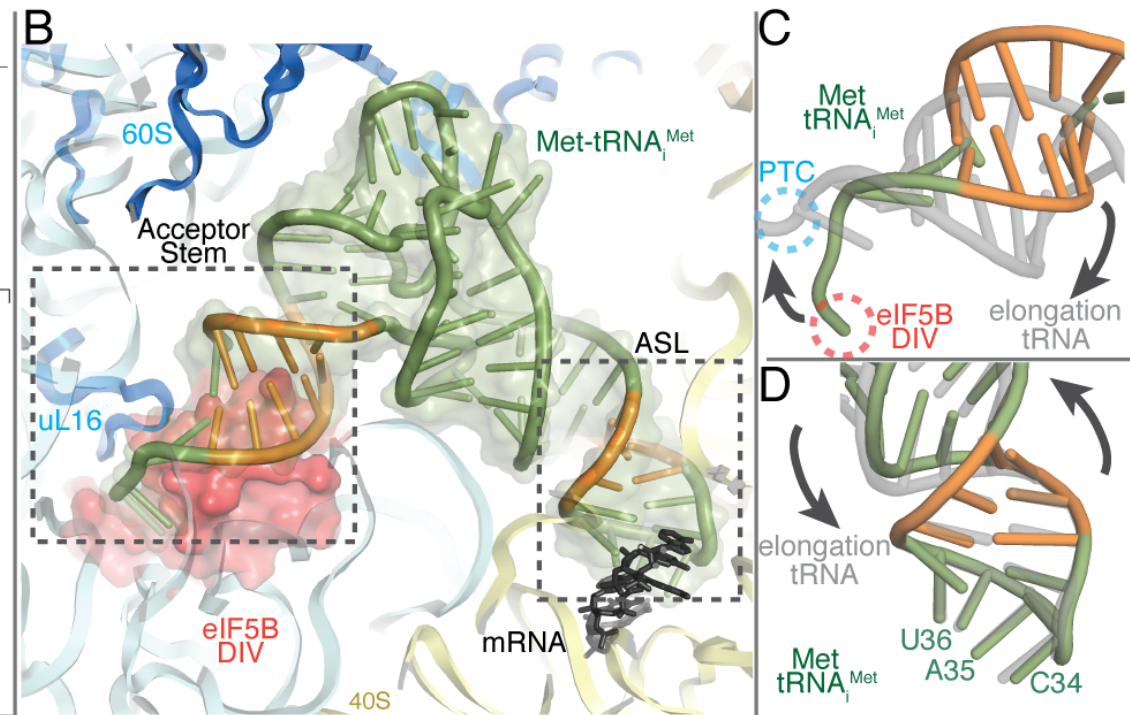

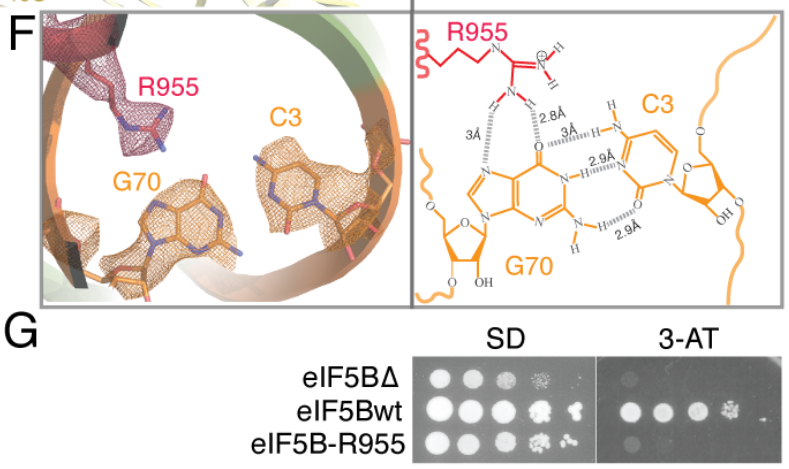


Wang et al.

Fig. 2. Role of the G-C base pairs clusters in Met-tRNA ${ }_{i}^{\text {Met }}$ conformation.

(A) Sequence diagram of the S. cerevisiae Met-tRNA ${ }_{i}{ }^{M e t}$ with initiator-specific base pairs colored in orange and modified nucleotides marked with asterisks. (B) Overview of the conformation adopted by Met-tRNA ${ }_{i}^{\text {Met }}$ on the $80 \mathrm{~S}-\mathrm{IC}$ complex with the initiator-specific G-C base pairs colored in orange. (C) Superposition of Met-tRNA ${ }_{i}{ }^{\text {Met }}$ (green) with a P site classical-state elongation tRNA (grey) reveals a distorted configuration of the acceptor stem of Met-tRNA ${ }_{i}{ }^{\text {et }}$ when compared with an elongation peptidyl-tRNA. This distortion prevents the ${ }_{74} \mathrm{CCA}_{76}$-Met end of Met-tRNA ${ }_{i}{ }^{\mathrm{Met}}$ from reaching the peptidyl transferase center (PTC, blue) on the 60S. (D) In contrast, the ASL of MettRNA $_{i}{ }^{\text {Met }}$ has reached it final position when compared with an elongation tRNA in the P site. (E) The arginine residue 955 at DIV of eIF5B specifically recognizes the Hoogsteen edge of the base of nucleotide G70 of Met-tRNA ${ }_{i}{ }^{\text {Met }}$ (red arrow, R955). (F) CryoEM density for side chains and individual bases in the area around eIF5B R955. On the right, chemical diagram with contacts and 
bioRxiv preprint doi: https://doi.org/10.1101/2020.05.30.125153; this version posted May 31, 2020. The copyright holder for this preprint (which

was not certified by peer review) is the author/funder, who has granted bioRxiv a license to display the preprint in perpetuity. It is made available under aCC-BY 4.0 International license.

Wang et al.

Figure 3.

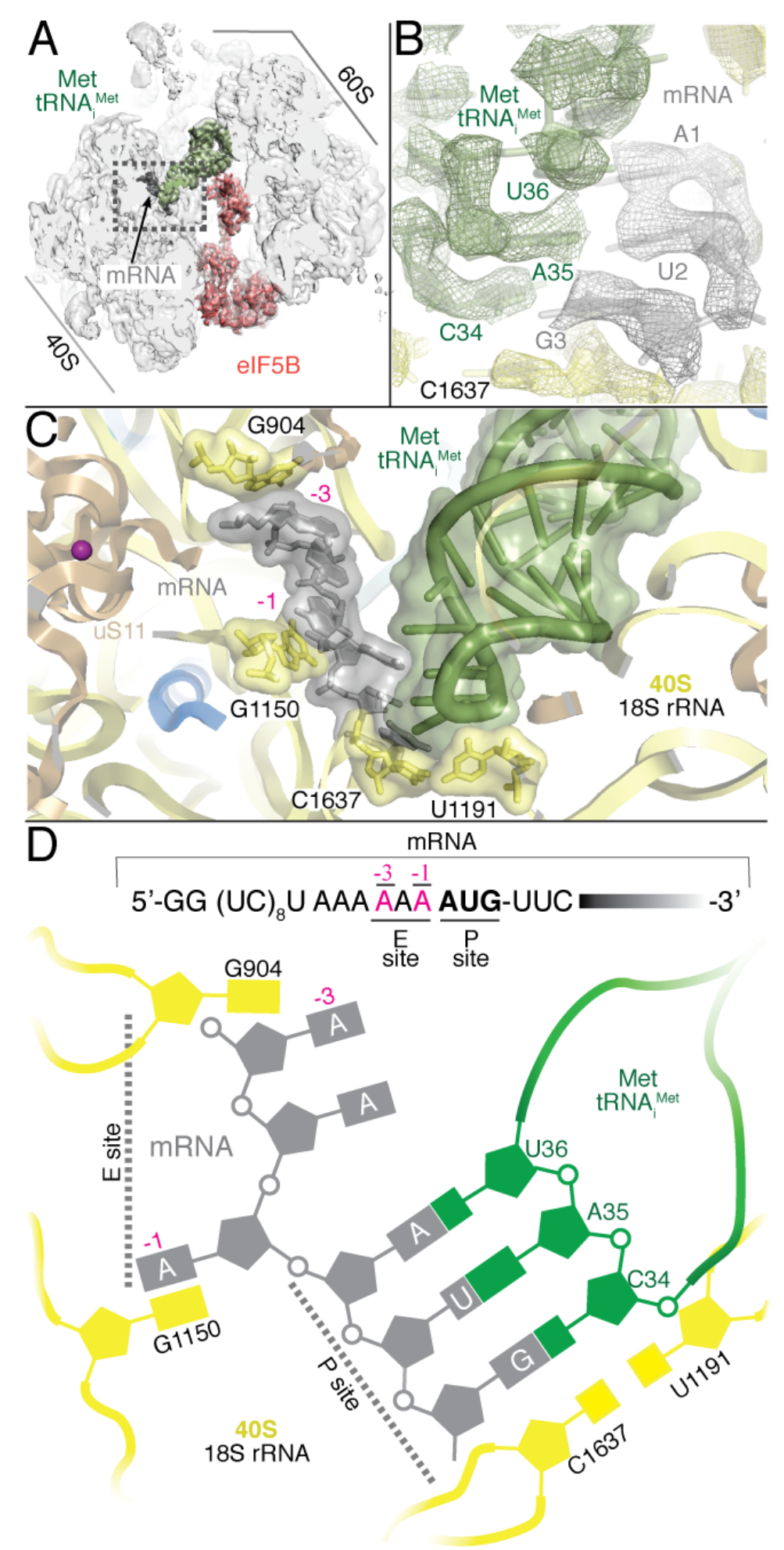


bioRxiv preprint doi: https://doi.org/10.1101/2020.05.30.125153; this version posted May 31, 2020. The copyright holder for this preprint (which

was not certified by peer review) is the author/funder, who has granted bioRxiv a license to display the preprint in perpetuity. It is made available under aCC-BY 4.0 International license.

Wang et al.

Fig. 3. mRNA nucleotides at positions -1/-3 play a key role in later stages of initiation.

(A) Overall view of the $80 \mathrm{~S} / \mathrm{Met}_{\mathrm{RNA}} \mathrm{Met} / \mathrm{eIF} 5 \mathrm{~B}$ complex in an orientation centered on the mRNA. (B) Detailed view of the small ribosomal subunit $\mathrm{P}$ site with experimental cryoEM density shown. The Met-tRNA ${ }_{i}{ }^{\text {Met }}$ ASL is in green, the start-codon grey and ribosomal bases of the small subunit yellow. (C) Overall view of the $\mathrm{P}$ and $\mathrm{E}$ sites of the small ribosomal subunit. Six bases

314 corresponding to the start codon of the mRNA and three preceding bases corresponding to nucleotides -1 to -3 showed unambiguous densities and could be modeled (grey). The final refined model with labeled components are shown. (D) Simplified schematic view of the conformation

317 adopted by the start codon in the $\mathrm{P}$ site and the preceding -1 to -3 bases in the $\mathrm{E}$ site in the presence 318 of eIF5B. 
bioRxiv preprint doi: https://doi.org/10.1101/2020.05.30.125153; this version posted May 31, 2020. The copyright holder for this preprint (which

was not certified by peer review) is the author/funder, who has granted bioRxiv a license to display the preprint in perpetuity. It is made available under aCC-BY 4.0 International license.

Wang et al.

Figure 4.

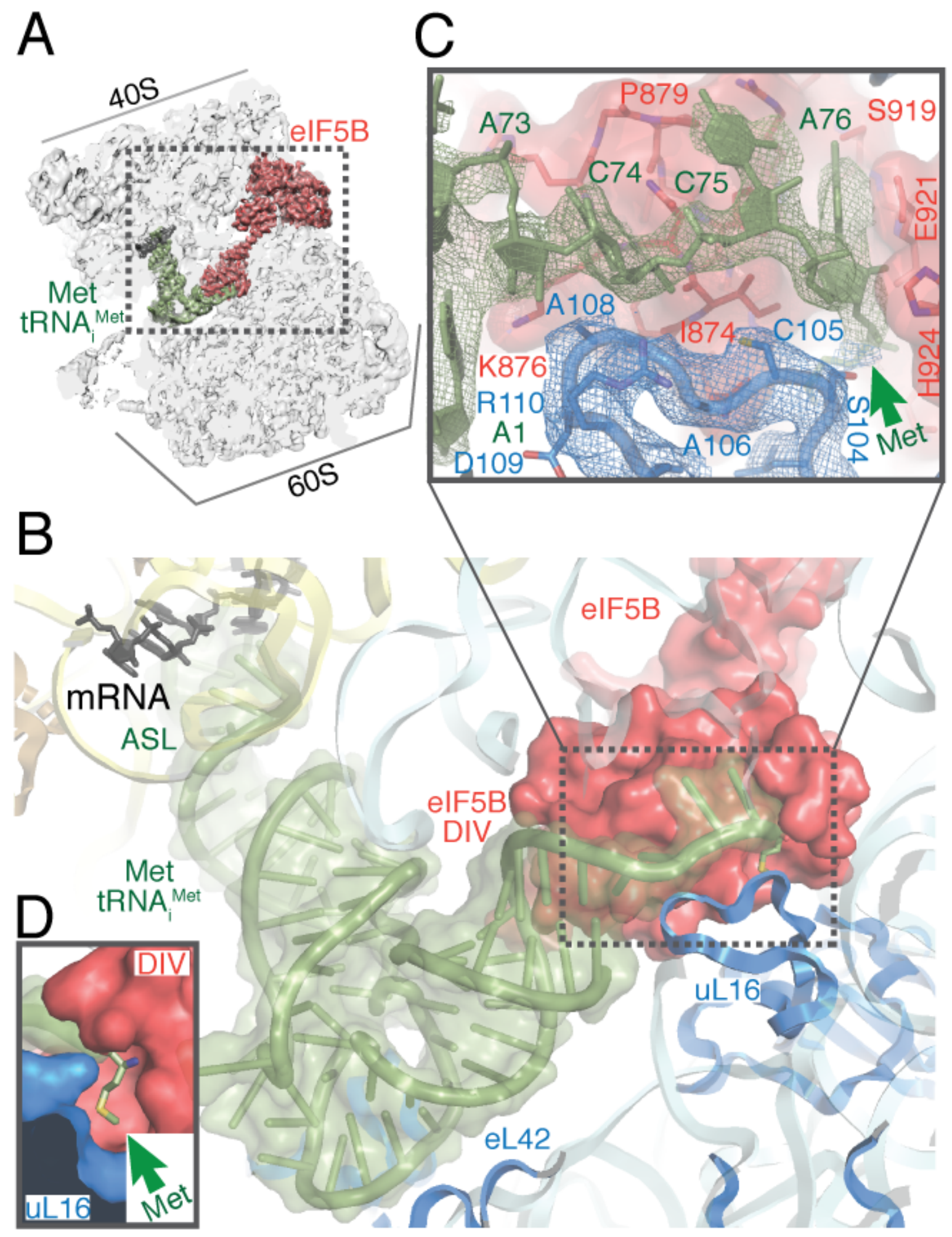


Wang et al.

Fig. 4. Ribosomal protein uL16 collaborates with eIF5B DIV in Met-tRNA ${ }_{i}^{\text {Met }}$ A76-Met check.

(A) Overall view of the $80 \mathrm{~S} /$ Met-tRNA ${ }_{i}{ }^{\text {Met }} / \mathrm{eIF} 5 \mathrm{~B}$ complex in an orientation centered on eIF5B interacts with the mRNA and eIF5B DIV on the 80S. (C) A detailed view of eIF5B DIV focused on the acceptor stem region of Met-tRNA ${ }_{i}{ }^{M e t}$. DIV of eIF5B is shown in red as semi-transparent

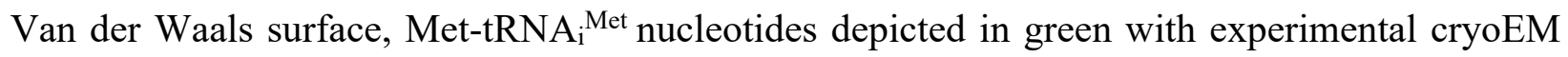

341 density shown and uL16 residues are in blue with experimental cryoEM density shown. DIV of eIF5B and residues 102-110 of uL16 form a hydrophobic cavity where the methionine residue of Met-tRNA ${ }_{i}^{\text {Met }}$ is hosted, as shown in (D).

\section{Acknowledgments.}

346 We are grateful to Dr. Dong-Hua Chen for technical support for sample freezing, and the cryoEM

347 facility staff at Columbia University Irving Medical Center (CUIMC) for excellent technical 348 assistance in cryoEM data acquisition. This work was supported by the US National Institutes of 349 Health (NIH) grants GM011378 and AI047365 to J.D.P.; a Knut and Alice Wallenberg Foundation 350 postdoctoral scholarship to J.W. (KAW 2015.0406); the Intramural Research Program of the NIH 351 (T.E.D). 


\section{Supplementary Materials for}

\section{Large ribosomal subunit, eIF5B, Met-tRNA ${ }_{i}^{\text {Met }}$ and mRNA}

\section{cooperate to complete accurate initiation.}

Jinfan Wang, Jing Wang, Byung-Sik Shin, Thomas E. Dever, Joseph D. Puglisi* and Israel S. Fernández ${ }^{*}$

*Corresponding authors. Email: puglisi@standford.edu, isf2106@cumc.columbia.edu

This PDF file includes:

Materials and Methods

Figs. S1 to S8

Movie S1

Table S1

References 


\section{Materials and Methods}

\section{Materials}

All the yeast Saccharomyces cerevisiae 40S and 60S ribosomal subunits, initiation factors eIF1, $1 \mathrm{~A}, 2,5$, and 5B, and mRNA were prepared and characterized as described (1). The model mRNAconsensus, with the sequence GG(UC) ${ }_{8}$ UAAAAAAAUGUUCAAAUAA(UC) $)_{16}$, was an uncapped, unstructured model mRNA containing the optimal yeast 5 ' context consensus sequence (underlined) with a biotin covalently linked to the 3'end (1). Native yeast methionylated initiator tRNA (Met-tRNA ${ }_{i}{ }^{\text {Met }}$ ) was purchased from tRNA Probes, LLC (MI-60).

\section{S:eIF5B complex assembly on model mRNA}

Previously by applying single-molecule fluorescence microscopy methods to a purified, reconstituted yeast translation system, we have revealed that eIF5B is the gating factor during the transition from eukaryotic translation initiation to elongation (1). We preformed post-scanning 48S preinitiation complexes (48S PICs, wherein 40S was labeled with a Cy3 dye) which were immobilized on zero-mode waveguides (ZMWs) imaging surface via a biotin at the 3 'end of the mRNAs (Fig. S1, A) (1). After washing away unbound components, 60S (Cy5-labeled), eIF5B (Cy5.5-labeled) and the first elongator Phe-tRNA ${ }^{\text {Phe }}$ (Cy3.5-labeled) in ternary complex with the elongation factor eEF1A and GTP (Phe-TC) were delivered along with required eIFs to start the reaction. By directly illuminating all the fluorescent dyes, we could monitor, in real time, the order of molecular events occurring during the late translation initiation stages and its transition to elongation (Fig. S1, B) (1). This allowed us to measure and determine the occupancy times of eIF5B on newly formed $80 \mathrm{~S}$ complexes on the native reaction pathway. In particular, for the model mRNA-Kozak, the mean time of $60 \mathrm{~S}$ joining to form an $80 \mathrm{~S}$ was $\sim 16 \mathrm{~s}$ with the eIF5B occupancy time on the $80 \mathrm{~S} \sim 34 \mathrm{~s}$ at $20^{\circ} \mathrm{C}$ and $3 \mathrm{mM}$ free $\mathrm{Mg}^{2+}$; whereas these values were $\sim 3.6 \mathrm{~s}$ and $68.7 \mathrm{~s}$, respectively, at $20^{\circ} \mathrm{C}$ and $10 \mathrm{mM}$ free $\mathrm{Mg}^{2+}(1)$. Simulating the kinetic curves from these two reactions provided the information about the time-evolution of the populations of different complexes (Fig. S1, C) (1). To aid the reconstruction of a high resolution structure of the onpathway eIF5B-bound $80 \mathrm{~S}$ prior to its transition to elongation without the need of nonhydrolysable GTP analogs or mutants, we decided to prepare and freeze our sample at timepoint $40 \mathrm{~s}$ at $20^{\circ} \mathrm{C}$ and $10 \mathrm{mM}$ free $\mathrm{Mg}^{2+}$, where we would expect the eIF5B-bound $80 \mathrm{~S}$ population accounts $\sim 60 \%$ of the total 80 S particles (Fig. S1, C).

Samples were prepared in the buffer containing $30 \mathrm{mM}$ HEPES-KOH pH 7.5, $100 \mathrm{mM} \mathrm{KOAc,} 10$ $\mathrm{mM} \mathrm{Mg}(\mathrm{OAc})_{2}$ and $1 \mathrm{mM} \mathrm{GTP}: \mathrm{Mg}^{2+}$. First, a ternary complex mixture was prepared by preincubating $3.8 \mu \mathrm{M}$ eIF2 at $30^{\circ} \mathrm{C}$ for $10 \mathrm{~min}$, followed by another $5 \mathrm{~min}$ incubation at $30^{\circ} \mathrm{C}$ after

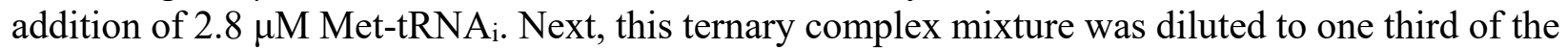
concentration, and incubated at $30^{\circ} \mathrm{C}$ together with $1 \mu \mathrm{M}$ eIF $1,1 \mu \mathrm{M}$ eIF1A, $0.5 \mu \mathrm{M}$ model mRNA and $0.3 \mu \mathrm{M} 40 \mathrm{~S}$ for $15 \mathrm{~min}$, resulting a 48S PIC mixture. Separately, a $60 \mathrm{~S}$ mixture was prepared by mixing $1 \mu \mathrm{M}$ eIF5, $1 \mu \mathrm{M}$ eIF5B and $0.15 \mu \mathrm{M} 60 \mathrm{~S}$. The 48S PIC and 60S mixtures were kept on ice before sample freezing. In parallel, the 200-mesh Quantifoil R2/1 grids (Electron Microscopy Sciences, Q250AR1) were glow-discharged for $25 \mathrm{~s}$ in a PELCO easiGlow glow discharger (Ted Pella, Inc.). After prewarming the samples to room temperature, $3.5 \mu \mathrm{L}$ of the $48 \mathrm{~S}$ PIC mixture was mixed with $3.5 \mu \mathrm{L}$ of the $60 \mathrm{~S}$ mixture. A $3 \mu \mathrm{L}$ sample from the resulted mixture was applied to each grid at $21{ }^{\circ} \mathrm{C}$ and $95 \%$ humidity. The sample was vitrified by plunging into liquid ethane after $2.5 \mathrm{~s}$ blotting using a Leica EM GP (Leica Microsystems) plunger. Total time from combining the 48S PIC and 60S mixtures to grid freezing was $\sim 40 \mathrm{~s}$. 
$\underline{\text { Single-molecule experiments comparing Met-tRNA }}{ }_{i}{ }_{\text {Met }}$ and Gly-tRNA ${ }_{i}{ }^{\text {Met }}$. Native yeast tRNA ${ }_{i}^{\text {Met }}$ was mis-acylated by the flexizyme dFx with Gly-DBE as described (2, 3). Real-time single-molecule experiments on the ZMW-based PacBio RSII instrumentation and data analyses were performed with exactly the same methodology as previously described (1). The mean times of $60 \mathrm{~S}$ arrival to the immobilized 48S PICs (60S arrival time) and the subsequent transition to elongation $(\Delta t$, Fig.S1, B) were determined in experiments performed with the model mRNA-Kozak and unlabeled eIF5B at $3 \mathrm{mM}$ free $\mathrm{Mg}^{2+}$ and $20^{\circ} \mathrm{C}$.

Generation of eIF5B mutant and growth experiments in yeast.

The Saccharomyces cerevisiae fun124 strain J111 (MATa ura3-52 leu2-3 leu2-112 fun124) (2) lacking eIF5B was transformed with an empty vector (eIF5B $\Delta$ ) or plasmids expressing $\mathrm{N}$ terminally deleted (lacking residues 28-396) form of wild-type (WT) eIF5B (4) or the eIF5BR955A mutant, as indicated. Transformants were grown to saturation, and $5 \mu 1$ of serial dilutions (of $\mathrm{OD}_{600 \mathrm{~nm}}=1.0,0.1,0.01,0.001$, and 0.0001) were spotted on minimal medium supplemented with essential nutrients (SD) or medium containing $10 \mathrm{mM} \mathrm{3-aminotriazole} \mathrm{(3-AT)} \mathrm{to} \mathrm{cause}$ histidine starvation. Plates were incubated 3 days at $30^{\circ} \mathrm{C}$.

Image processing and structure determination.

Contrast transfer function parameters were estimated using CTFIND4 (5) and particle picking was performed using Relion3.1(6) without the use of templates and with a diameter value of 260 Ångstrongs. All 2D and 3D classifications and refinements were performed using RELION (6-8). An initial 2D classification with a 4 times binned dataset identified all ribosome particles. A consensus reconstruction with all $80 \mathrm{~S}$ particles was computed using the AutoRefine tool of RELION. Next, 3D classification without alignment and a mask including the inter-subunit space and the 40S head (four classes, $\mathrm{T}$ parameter 4) identified a class with unambiguous density for eIF5B and a tRNA in the P site (7). This class was independently processed with unbinned data, yielding high resolution maps with density features in agreement with the reported resolution. Local resolution was computed with RESMAP (9).

Model building and refinement. Models from yeast 40S, 60S (10), tRNA $_{\mathrm{i}}$ and eIF5B were docked into the maps using CHIMERA (11), and COOT (12) was used to manually adjust these initial models. An initial round of refinement was performed in Phenix using real-space refinement (13) with secondary structure restraints and a final step of reciprocal-space refinement with REFMAC (14). The fit of the model to the map over-fitting tests were performed following standard protocols in the field (15). 
A
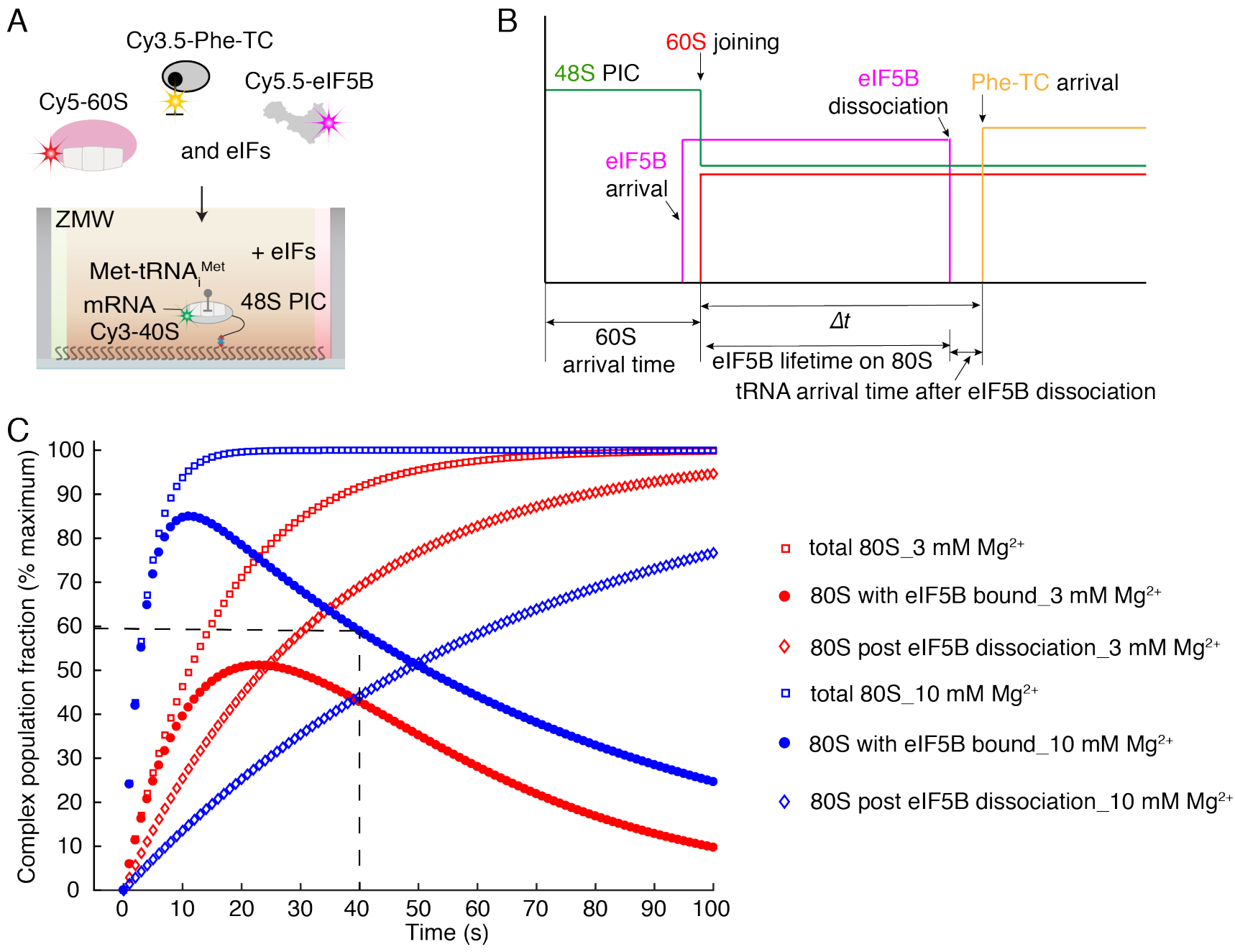

Fig. S1. CryoEM sample preparation guided by single-molecule dynamics. (A) Singlemolecule fluorescence microscopy experimental set up and (B) representative schematic experimental trace with the molecular events annotated (1). Mean times for subunit joining to form the $80 \mathrm{~S} \mathrm{IC} \mathrm{(60S} \mathrm{arrival} \mathrm{time)} \mathrm{and} \mathrm{subsequent} \mathrm{transition} \mathrm{into} \mathrm{elongation} \mathrm{(} \Delta t$, signaled by the arrival of the first elongator Phe-TC) were estimated. $\Delta t$ is obtained by the addition of the eIF5B lifetime on $80 \mathrm{~S}$ and the tRNA arrival time after eIF5B dissociation, with the latter being much smaller than the former. (C) Simulated time-evolution of $80 \mathrm{~S}$ complex populations based on the previously determined kinetics in experiments performed with the model mRNA-Kozak at $20^{\circ} \mathrm{C}(1)$. Informed by our kinetics measurements, cryoEM samples corresponding to the timepoint $40 \mathrm{~s}$ after mixing 48S PICs, eIF5B:GTP and 60S in the presence of required eIFs at $10 \mathrm{mM}$ free $\mathrm{Mg}^{2+}$ and $20^{\circ} \mathrm{C}$ were frozen. Dashed line indicates the estimated timepoint when the $80 \mathrm{~S}$ population with eIF5B is $\sim 60 \%$. 


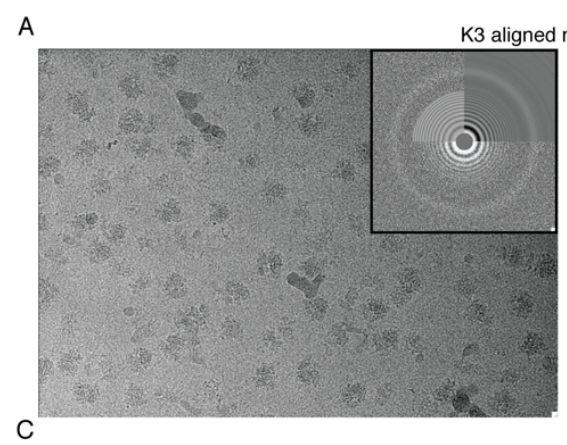

3D consensus
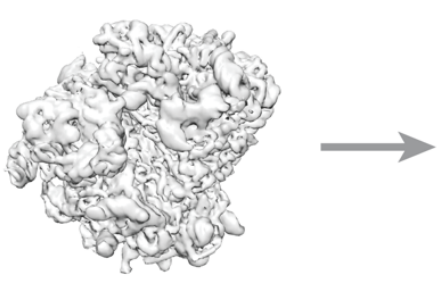

3D after classification and ctf refinement
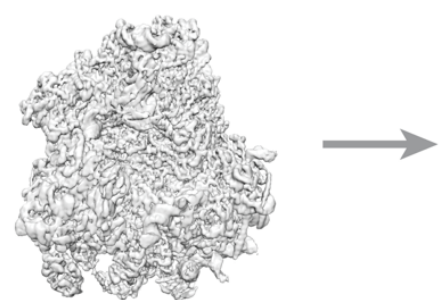

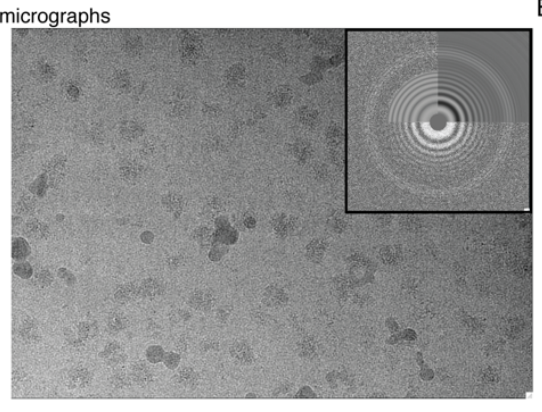

Masked classification without alignment C5 T3

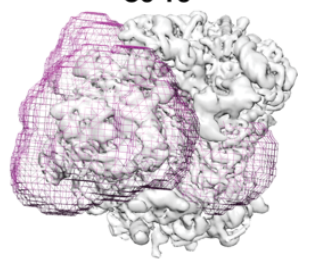

Local masked refinement for $40 \mathrm{~S}$

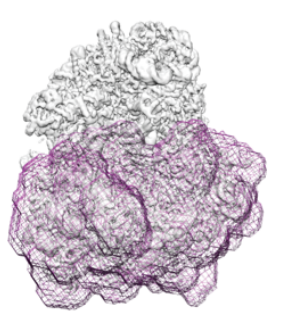

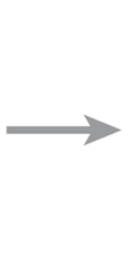

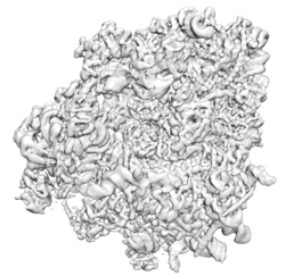

Reference-free 2D averages

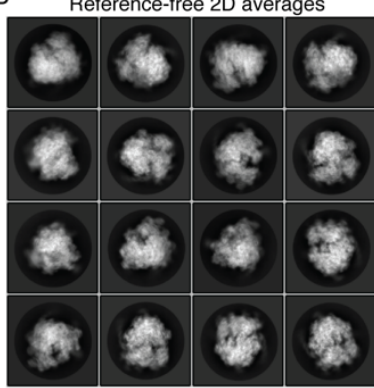

3D after classification

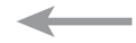
Composite map
(Chimera vop max option)
and post-proccesing

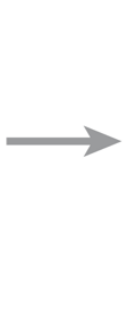

D
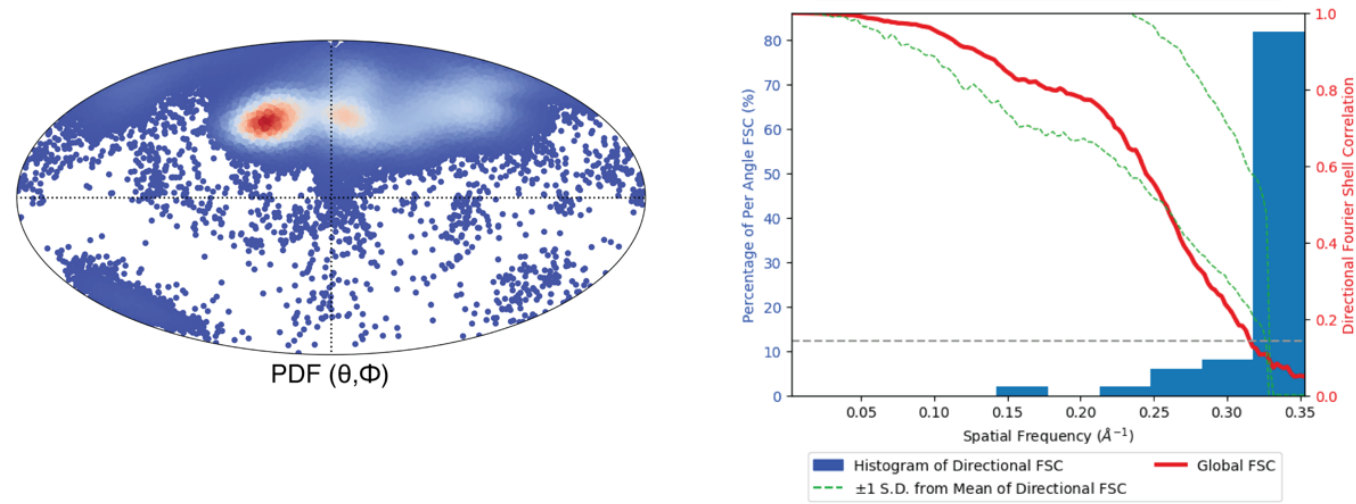

Fig. S2. Representative cryoEM images, reference-free 2D averages and image processing workflow.

(A) Motion corrected micrographs. (B) Selected 2D averages. (C) Classification workflow. (D) On the left, Eulerian angles distribution of the final class and on the right directional FSC (16). 
A

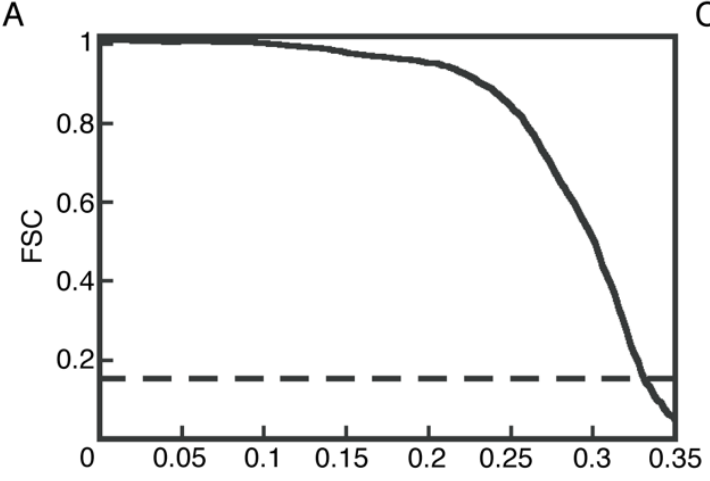

B

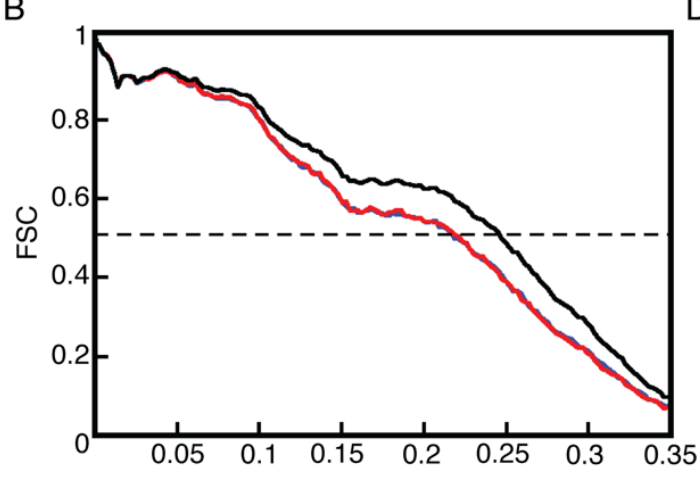

C

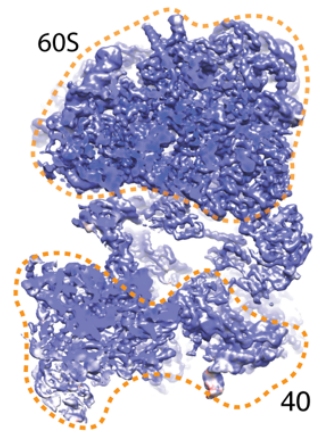

D

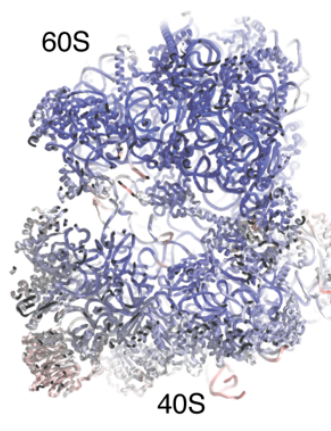

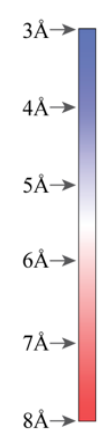
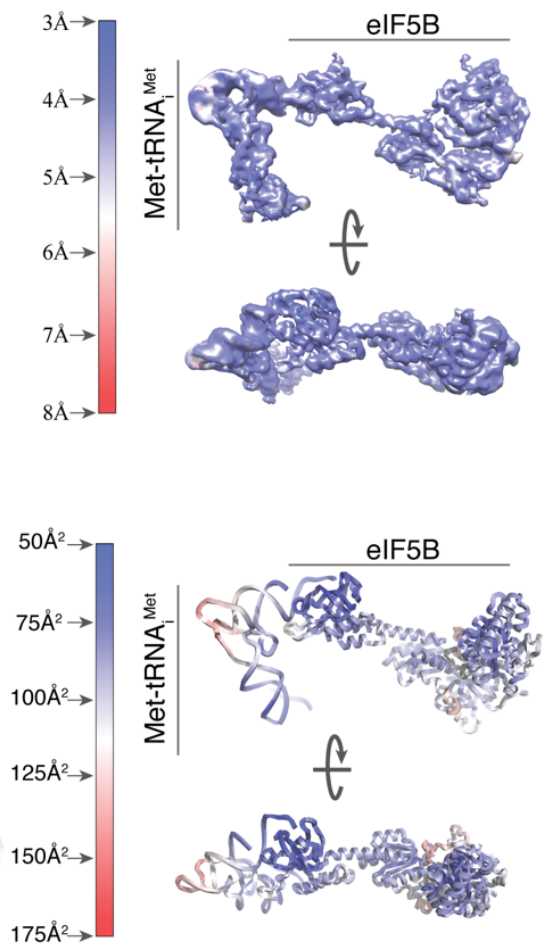

Fig. S3. Fourier Shelf Correlation curves, model validation and local resolution.

(A) Fourier Shell Correlation curve (FSC) for independently refined half-maps indicated a final resolution of 2.9 ̊. (B) Model validation FSC for the final "shacked" model and half-map 1 (blue line) and half-map 2 (red curve) not included in the refinement. Black line represents the FSC for the final model against the final, post-processed map used in model building and model refinement. The overlapping of the blue and red curve guarantees absence of overfitting in our model (15). (C) Unsharpened map colored according to local resolution calculations. On the right, a detailed view for the region of the map containing density for eIF5B and Met-tRNA ${ }_{i}{ }^{\text {Met }}$. (D) Final stereochemically refined model colored according to temperature (B) factors estimated by REFMAC (14). Regions of the model with higher B factors correlate with flexible areas of the map. 
A 605
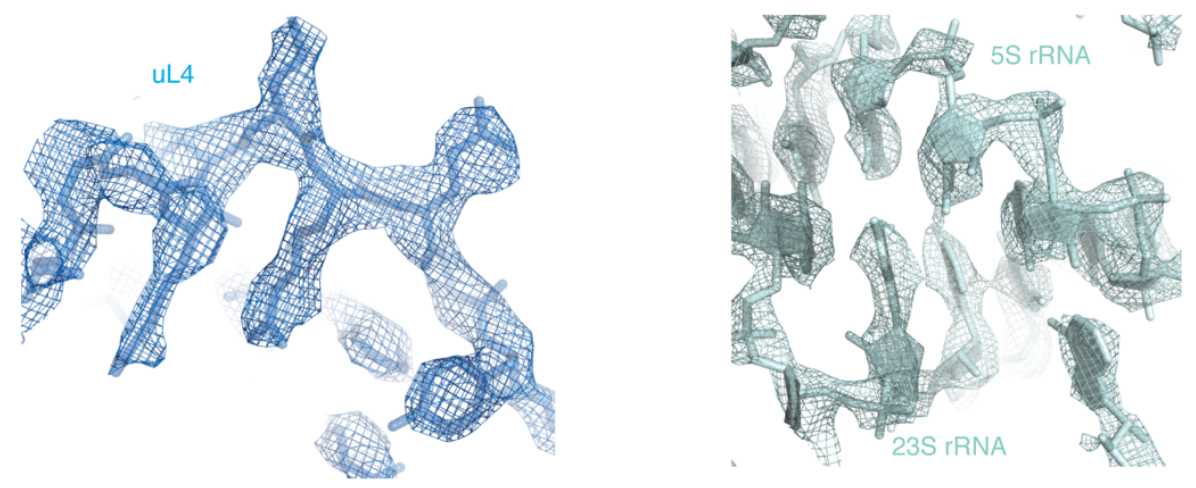

B $40 S$
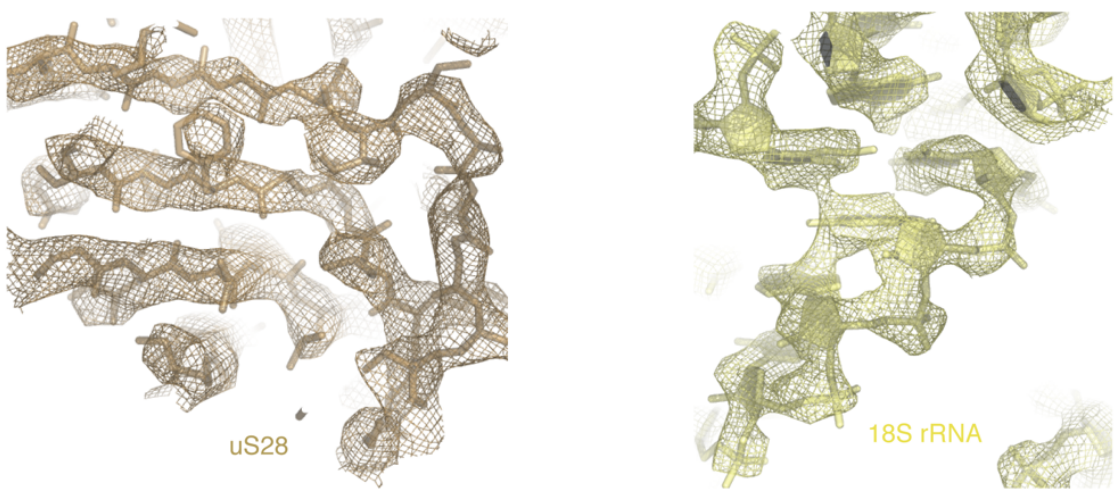

C elF5B
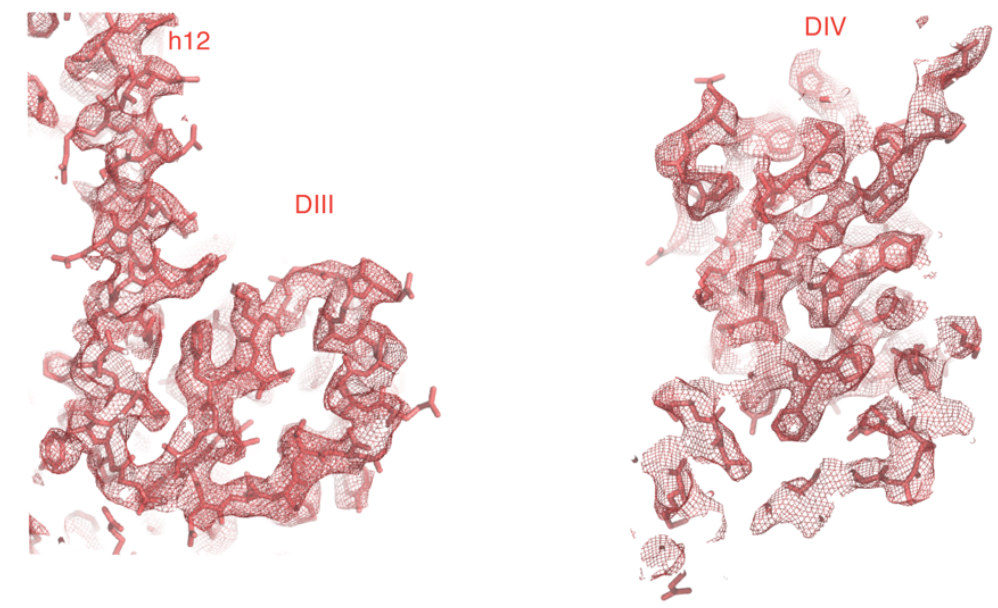

Fig. S4. CryoEM representative densities.

Final, post-processed cryoEM densities for: (A) 60S components, (B) 40S components and (C) eIF5B. 
A

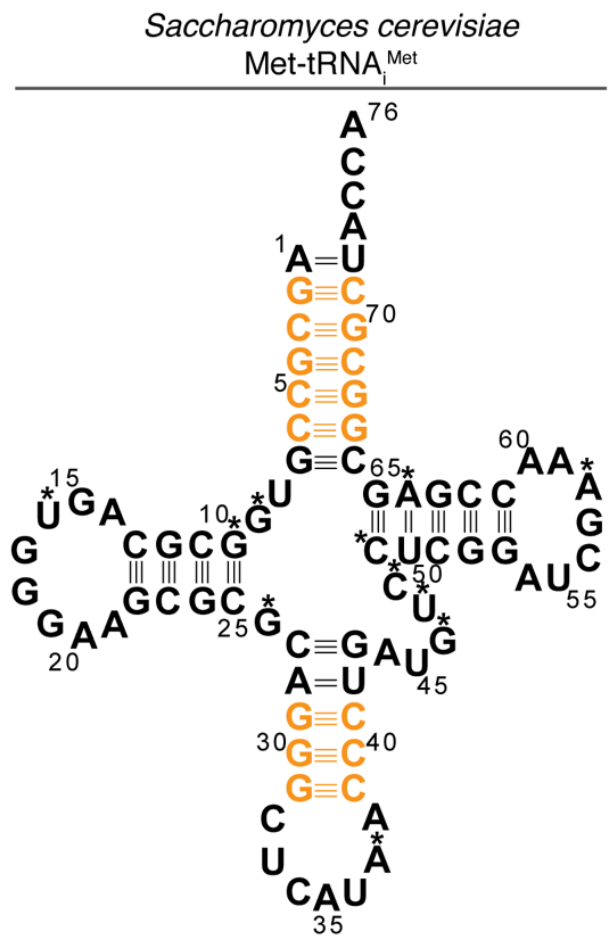

Initiation tRNA

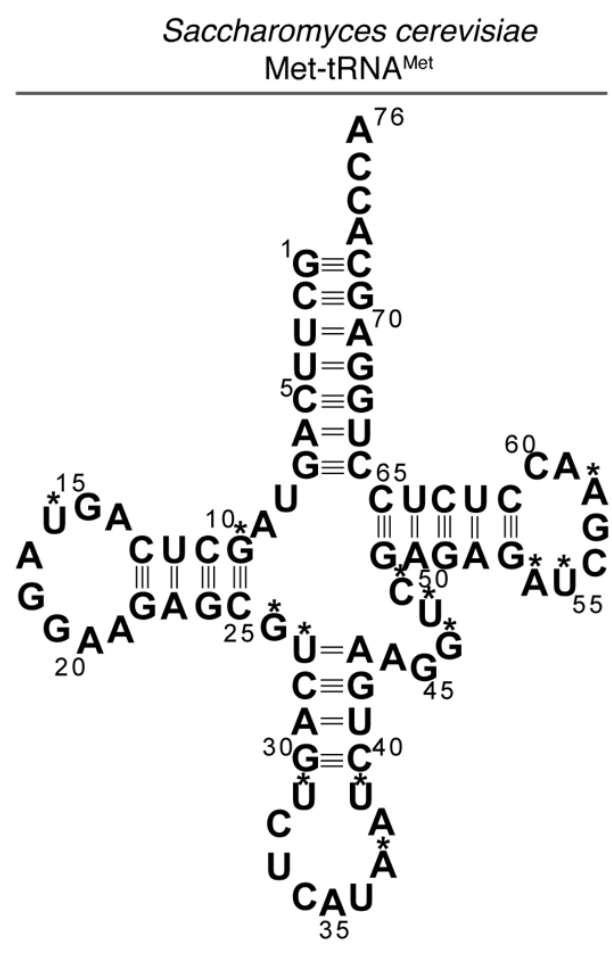

Elongation tRNA

B
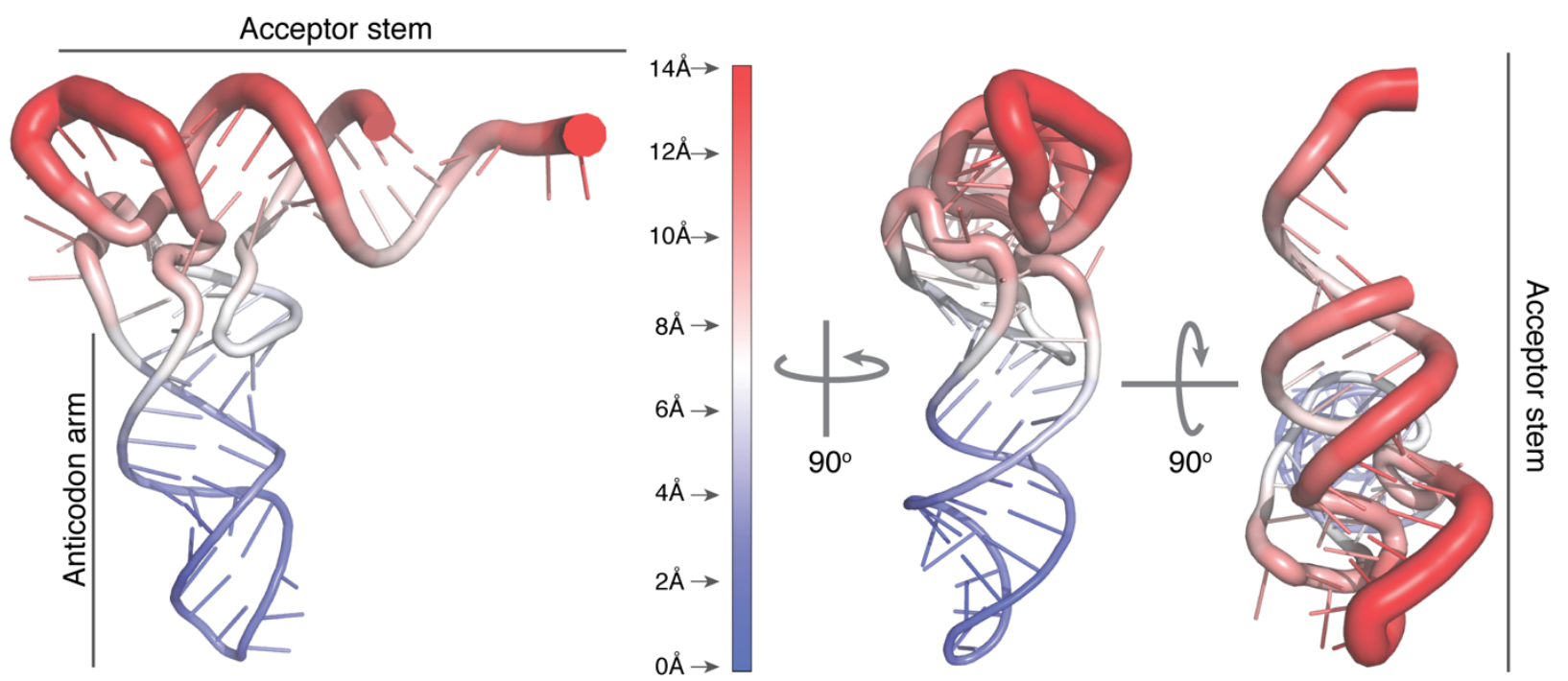

Fig. S5. Saccharomyces cerevisiae tRNA ${ }^{\text {Met }}$ sequences.

(A) Left, S.cerevisiae sequence for $\mathrm{tRNA}_{i}$ with the G-C base pair clusters unique to initiator tRNA in orange. Right, elongation tRNA ${ }^{\text {Met }}$ sequence in S.cerevisiae. Asterisks denote modified nucleotides. (B) Root mean square deviations (r.m.s.d) between atoms computed for tRNAi in an elongation configuration versus the configuration described in this work. Mayor differences are found within the acceptor stem. 


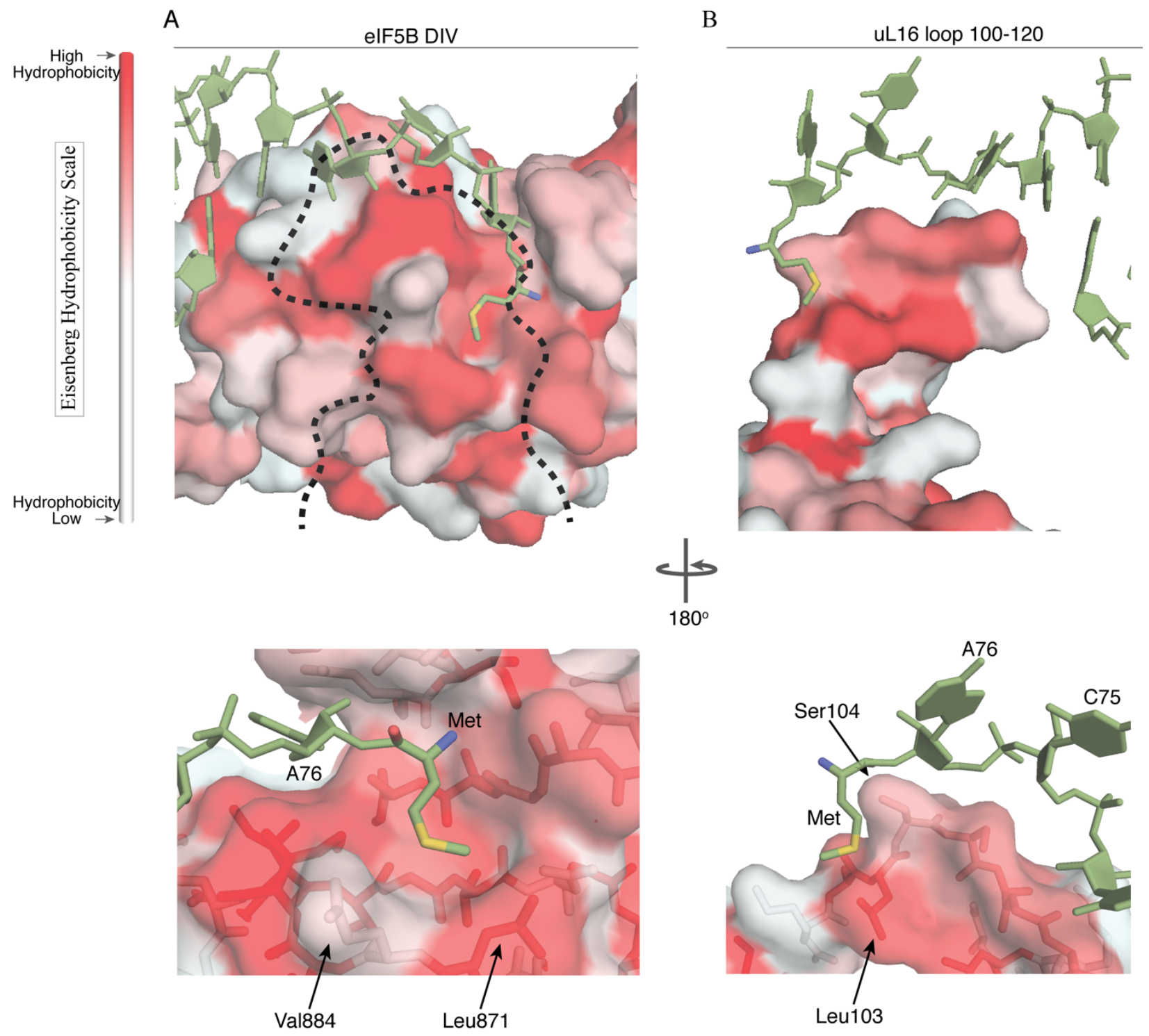

Fig. S6. Surface hydrophobicity calculations for eIF5B and uL16.

(A) eIF5B domain IV represented as Van der Waals surface colored according to the Eisenberg hydrophobicity scale. In sticks is shown Met-tRNA ${ }_{i}{ }^{M e t}(17)$. Indicated with a dash line is the position occupied by uL16 loop 100-120. (B) Same representation as in (A) from the uL16 view. Methionine residue esterified to the $3^{\prime} \mathrm{OH}$ of Met-tRNA ${ }_{i}{ }^{\text {Met }} \mathrm{A} 76$ is hosted in a highly hydrophobic cavity formed by eIF5B DIV and uL16 loop 100-120. 
A

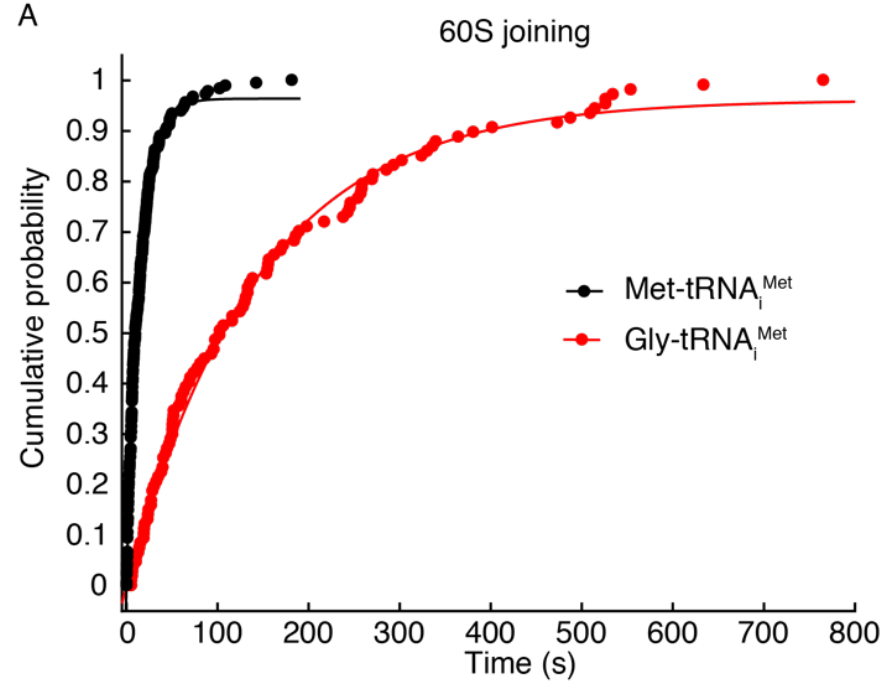

B

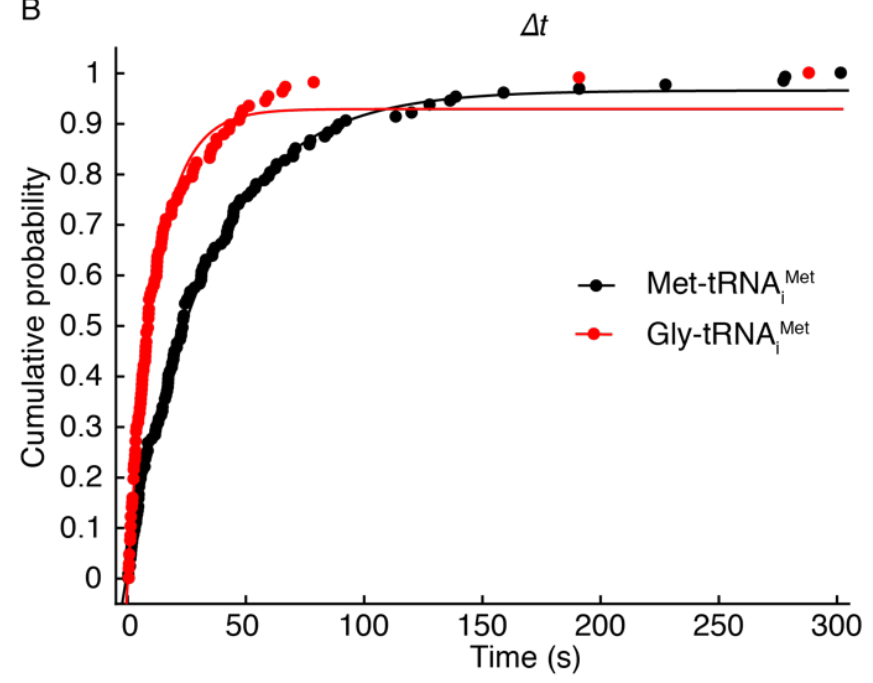

Fig. S7. Kinetics of subunit joining and subsequent transition into elongation in experiments performed with Met-tRNA ${ }_{i}{ }^{\text {Met }}$ and Gly-tRNA ${ }_{i}{ }^{\text {Met }}$.

The cumulative probability distributions of the dwell times for 60S joining (A) and the transition to elongation $(\Delta t, \mathbf{B})$ from experiments performed at $3 \mathrm{mM}$ free $\mathrm{Mg}^{2+}$ and $20{ }^{\circ} \mathrm{C}$ with the model mRNA-Kozak and dark eIF5B. Data points were fitted to a single-exponential equation. When Met-tRNA ${ }_{i}^{\text {Met }}$ was used, the mean $60 \mathrm{~S}$ arrival time was $14.8 \mathrm{~s} \mathrm{(} \pm 0.4 \mathrm{~s}, 95 \%$ confidence interval), with $\Delta t$ of $33.7 \mathrm{~s}( \pm 0.9 \mathrm{~s}, 95 \%$ confidence interval) (number of molecules analyzed $=127)$, similar to those values determined previously under the same experimental conditions (1). For GlytRNA $_{i}{ }^{\text {Met }}$ (red) the mean $60 \mathrm{~S}$ arrival time increased to $142.9 \mathrm{~s} \mathrm{(} \pm 6.2 \mathrm{~s}, 95 \%$ confidence interval), and $\Delta t$ decreased to $11.7 \mathrm{~s}( \pm 0.5 \mathrm{~s}, 95 \%$ confidence interval) (number of molecules analyzed $=$ 107). 
A
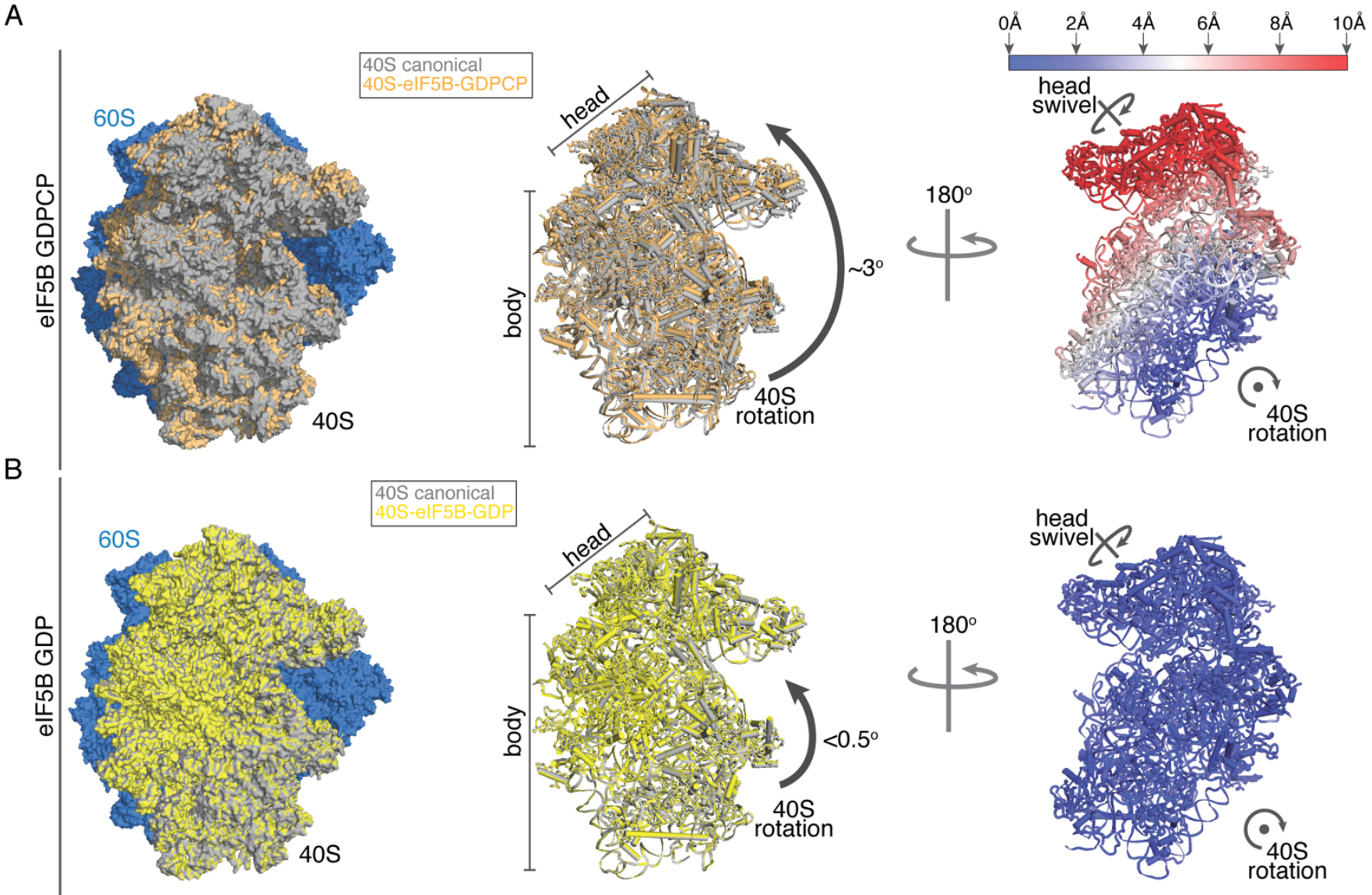

Fig. S8. 40S subunit rotation state in eIF5B containing complexes.

(A) In the presence of a non-hydrolysable GTP analog, binding of eIF5B to the 80S induces a moderate degree of $40 \mathrm{~S}$ rotation compared with a canonical state $(10,18)$. (B) In the present reconstruction, with eIF5B in the 80S complex and hydrolyzed GTP, the 40S subunit features an almost canonical configuration with very little rotation and/or head swivel. 


\section{Movie S1. Met-tRNA $A_{i}^{\text {Met }}$ transition from late initiation to elongation.}

The interaction DIV of eIF5B establishes with the acceptor stem of Met-tRNA ${ }_{i}{ }^{\text {Met }}$ keep the ${ }_{73} \mathrm{ACCA}_{76}$-Met of the tRNA away from the PTC (blue). Upon eIF5B departure, the ${ }_{73} \mathrm{ACCA}_{76}$-Met is free to accommodate in the PTC so the Met-tRNA ${ }_{i}^{\text {Met }}$ adopts a full elongation-competent conformation.

\section{Table S1. Cryo-EM data collection, refinement and validation statistics}

\begin{tabular}{|c|c|}
\hline & $\begin{array}{c}\text { EMDB-21859 } \\
\text { PDB 6WOO }\end{array}$ \\
\hline \multicolumn{2}{|l|}{ Data collection and processing } \\
\hline Magnification & 130,000 \\
\hline Voltage (kV) & 300 \\
\hline Electron exposure $\left(\mathrm{e}-/ \AA^{2}\right)$ & 49.43 \\
\hline Defocus range $(\mu \mathrm{m})$ & $-0.5 /-2$ \\
\hline Pixel size $(\AA))$ & 0.83 \\
\hline Symmetry imposed & $\mathrm{C} 1$ \\
\hline Initial particle images (no.) & 289,689 \\
\hline Final particle images (no.) & 190,058 \\
\hline Map resolution $(\AA)$ & 2.9 \\
\hline FSC threshold & 0.143 \\
\hline Map resolution range $(\AA ̊)$ & $3-8$ \\
\hline \multicolumn{2}{|l|}{ Refinement } \\
\hline Initial model used (PDB code) & $4 \mathrm{~V} 7 \mathrm{R}$ \\
\hline Model resolution $(\AA)$ & 3.3 \\
\hline FSC threshold & 0.5 \\
\hline Model resolution range $(\AA)$ & $3-8$ \\
\hline Map sharpening $B$ factor $\left(\AA^{2}\right)$ & -78.24 \\
\hline \multicolumn{2}{|l|}{ Model composition: } \\
\hline Non-hydrogen atoms & 211,067 \\
\hline Ligands & 52 \\
\hline \multicolumn{2}{|l|}{$B$ factors $\left(\AA^{2}\right)$ : } \\
\hline Protein & 109.4 \\
\hline RNA & 101.1 \\
\hline \multicolumn{2}{|l|}{ R.m.s. deviations: } \\
\hline Bond lengths $(\AA)$ & 0.010 \\
\hline Bond angles $\left({ }^{\circ}\right)$ & 1.43 \\
\hline \multicolumn{2}{|l|}{ Validation } \\
\hline MolProbity score & 2.42 \\
\hline Clashscore & 3.98 \\
\hline Poor rotamers (\%) & 6.43 \\
\hline \multicolumn{2}{|l|}{ Ramachandran plot: } \\
\hline Favored (\%) & 87.77 \\
\hline Allowed (\%) & 98.13 \\
\hline Disallowed (\%) & 1.86 \\
\hline \multicolumn{2}{|l|}{ RNA validation: } \\
\hline Angles outliers (\%) & 0.19 \\
\hline Sugar puckers outliers (\%) & 2.05 \\
\hline Average suit & 0.456 \\
\hline
\end{tabular}




\section{References.}

1. J. Wang et al., eIF5B gates the transition from translation initiation to elongation. Nature 573, 605-608 (2019).

2. J. Choi et al., Dynamics of the context-specific translation arrest by chloramphenicol and linezolid. Nat Chem Biol 16, 310-317 (2020).

3. H. Murakami, A. Ohta, H. Ashigai, H. Suga, A highly flexible tRNA acylation method for non-natural polypeptide synthesis. Nat Methods 3, 357-359 (2006).

4. B. S. Shin et al., Intragenic suppressor mutations restore GTPase and translation functions of a eukaryotic initiation factor 5B switch II mutant. Mol Cell Biol 27, 16771685 (2007).

5. A. Rohou, N. Grigorieff, CTFFIND4: Fast and accurate defocus estimation from electron micrographs. J Struct Biol 192, 216-221 (2015).

6. J. Zivanov et al., New tools for automated high-resolution cryo-EM structure determination in RELION-3. Elife 7, (2018).

7. S. H. Scheres, Processing of Structurally Heterogeneous Cryo-EM Data in RELION. Methods Enzymol 579, 125-157 (2016).

8. J. Zivanov, T. Nakane, S. H. W. Scheres, Estimation of high-order aberrations and anisotropic magnification from cryo-EM data sets in RELION-3.1. IUCrJ 7, 253-267 (2020).

9. A. Kucukelbir, F. J. Sigworth, H. D. Tagare, Quantifying the local resolution of cryo-EM density maps. Nat Methods 11, 63-65 (2014).

10. B. Y. Huang, I. S. Fernandez, Long-range interdomain communications in eIF5B regulate GTP hydrolysis and translation initiation. Proc Natl Acad Sci U S A 117, 1429-1437 (2020).

11. E. F. Pettersen et al., UCSF Chimera--a visualization system for exploratory research and analysis. J Comput Chem 25, 1605-1612 (2004).

12. P. Emsley, K. Cowtan, Coot: model-building tools for molecular graphics. Acta Crystallogr D Biol Crystallogr 60, 2126-2132 (2004).

13. P. V. Afonine et al., Real-space refinement in PHENIX for cryo-EM and crystallography. Acta Crystallogr D Struct Biol 74, 531-544 (2018).

14. R. A. Nicholls, F. Long, G. N. Murshudov, Low-resolution refinement tools in REFMAC5. Acta Crystallogr D Biol Crystallogr 68, 404-417 (2012).

15. A. Brown et al., Tools for macromolecular model building and refinement into electron cryo-microscopy reconstructions. Acta Crystallogr D Biol Crystallogr 71, 136-153 (2015).

16. Y. Z. Tan et al., Addressing preferred specimen orientation in single-particle cryo-EM through tilting. Nat Methods 14, 793-796 (2017).

17. D. Eisenberg, E. Schwarz, M. Komaromy, R. Wall, Analysis of membrane and surface protein sequences with the hydrophobic moment plot. J Mol Biol 179, 125-142 (1984).

18. I. S. Fernandez et al., Molecular architecture of a eukaryotic translational initiation complex. Science 342, 1240585 (2013). 